\title{
Decompositions of soft sets and soft matrices with applications in group decision making
}

\author{
Akın Osman Atagün ${ }^{1}$, Hüseyin Kamac1 ${ }^{2, *}$ \\ ${ }^{1}$ Department of Mathematics, Kırşehir Ahi Evran University, Kırşehir, Turkey \\ E-mail: aosman.atagun@ahievran.edu.tr \\ ${ }^{2}$ Department of Mathematics, Faculty of Science and Arts, \\ Yozgat Bozok University, Yozgat, Turkey \\ E-mail: huseyin.kamaci@hotmail.com \\ Tel: +9035424210 21, Fax: +903542421022
}

\begin{abstract}
The decompositions of soft sets and soft matrices are important tools for theoretical and practical studies. In this paper, firstly, we study the decomposition of soft sets in detail. Later, we introduce the concepts of $\alpha$ upper, $\alpha$-lower, $\alpha$-intersection and $\alpha$-union for soft matrices and present some decomposition theorems. Some of these operations are set-restricted types of existing operations of soft sets/matrices, others are $\alpha$-oriented operations that provide functionality in some cases. Moreover, some relations of decompositions of soft sets and soft matrices are investigated and the newfound relations are supported with numerical examples. Finally, two new group decision making algorithms based on soft sets/matrices are constructed, and then their efficiency and practicality are demonstrated by dealing with real life problems and comparison analysis. By using these proposed approaches, solutions can be presented to soft set-based multi-criteria decision making problems, both ordinary and involving primary assessments. These allow to handle soft set-based multi-criteria decision making from different perspectives.
\end{abstract}

Keywords: Soft set, soft matrix, decomposition of soft sets, decomposition of soft matrices, decision making.

\section{Introduction}

Many problems encountered in real-life scenarios contain ambiguity or unknown data. Sometimes existing mathematical models are insufficient to deal with such situations, and therefore new models are developed. Zadeh [1] proposed fuzzy sets as a powerful and effective approach for modeling uncertainty, and in the following years, the general forms of these sets were studied (e.g., [2-6]). In 1999, Molodtsov [7] initiated the theory of soft set to parametrically classify objects (or elements of the universe) in uncertain environments. Since these sets classify alternatives according to parameters (attributes), they can be easily applied to many different areas. In 2003, Maji et al. [8] published a seminal paper on the adaptation of set operations for soft sets. In the following years, Ali et al. [9] and Pei and Miao [10] contributed to operational research by developing different types of intersection and union of soft sets. In [11-13] the authors focused on the operations of difference and symmetric difference on the soft sets. Aygün and Kamac1 [14] introduced some generalized operations of the soft sets and discussed their related characteristic properties. In 2010, Çag̃man and Enginog̃lu [15] revisited some of the operations of Molodtsov's soft set to make them more useful in some situations. Feng et al. [16] studied

\footnotetext{
${ }^{*}$ Corresponding author.
} 
attribute analysis of information systems based on the soft sets and logical formulas over them. In 2007, Aktaş and Çag̃man [17] compared soft sets to fuzzy sets and rough sets, gave some basic concepts of soft set theory and defined the concept of soft group. In the following years, many papers were published on soft algebraic structures such as soft intersection semigroups [18-20], soft semirings [21], soft rings [22,23], soft near-rings [24], soft intersection Lie algebras [25], soft lattices [26-28], soft uni-Abel-Grassmann's groups [29], soft graphs [30,31], soft BCK/BCI-algebras [32-34], soft BL-algebras [35]. Moreover, many researchers were studied on the extended models of soft sets such as fuzzy soft sets [36-38], intuitionistic fuzzy soft sets [39-42], T-spherical soft sets [43], neutrosophic soft sets $[44,45]$, three-valued soft sets [46] and N-soft sets [47-50] and new researches are currently ongoing.

In recent years, Çag̃man and Enginog̃lu [51] published a seminal article on the matrix representations of soft sets, and thus they argued that in some cases, the use of matrix operations matching soft set operations can provide practicality to the calculations. Furthermore, they developed a matrix-based soft max-min decision making algorithm to deal with decision making problems under the soft set environment. Atagün et al. [52] constructed the soft distributive max-min decision making algorithm improving the algorithm proposed in [51]. In 2018, Kamaci et al. [53] introduced the row-products of soft matrices, and then proposed a novel decision making algorithm that can obtain an optimal choice from each of the disjoint sets of alternatives with respect to the specified parameters. Petchimuthu and Kamaci $[54,55]$ developed some multicriteria decision making procedures based on the $r$-product and $c$-product of inverse (fuzzy) soft matrices. In [56-59], the authors derived some basic operations of soft matrices and proposed solutions to decision making problems by using these new operations. At present, the studies on the theories of soft set and soft matrix are progressing rapidly in both theoretical and practical aspects.

The set-oriented approaches based on inclusion, restriction and extension of soft sets allow the expansion of the range of operations, algebraic structures, topological structures, application aspects of soft sets. Supporting this idea, Sezer et al. [20] described the lower $\alpha$-inclusion and upper $\alpha$-inclusion of a soft sets over the universal set $U$, where $\alpha \subseteq U$. Moreover, by using the upper $\alpha$-inclusion of a soft set, they introduced the upper $\alpha$-semigroups, upper $\alpha$-ideals and upper $\alpha$ bi-ideals of soft sets. The emergence of $\alpha$-inclusion of soft sets leads to the idea that the fundamentals of soft sets can be revisited so that the $\alpha$-oriented operations/structures of soft sets can be proposed. This paper aims to contribute to the theories of soft set and soft matrix by introducing new concepts, such as the $\alpha$-intersection and $\alpha$-union of soft sets, and the $\alpha$-upper, $\alpha$-lower, $\alpha$-intersection and $\alpha$-union soft matrices. Thus, initial findings and results of decompositions of soft sets and soft matrices are presented. By employing the proposed $\alpha$-oriented concepts, new decision making algorithms are elaborated and then their applicability to real-world problems are illustrated.

The rest of this paper is arranged as follows. Section 2 reviews the concepts of soft sets and soft matrices. Sections 3 and 4 are devoted to theoretical findings on the decompositions of soft sets and soft matrices, respectively. Section 5 presents set-restricted soft decision making models with applications and comparative study. Section 6 gives the concluding remarks.

\section{Preliminaries}

In this section, we review some basic concepts for future sections.

Definition 2.1. ( $[7,15])$ Let $U=\left\{\hbar_{i} \mid i=1,2, \ldots, m\right\}$ be an initial universe set, $\mathfrak{X}=\left\{x_{j} \mid j=1,2, \ldots, n\right\}$ be a set of parameters (attributes), $P(U)$ be the power set of $U$ and $A \subseteq \mathfrak{X}$. A soft set $(F, A)$ or simply $F_{A}$ on the universe $U$ is defined as the ordered pairs

$$
(F, A)=\left\{\left(x, f_{A}(x)\right) \mid x \in \mathfrak{X}, f_{A}(x) \in P(U)\right\},
$$

where $f_{A}(x): \mathfrak{X} \rightarrow P(U)$ such that $f_{A}(x)=\emptyset$ if $x \notin A$. Here $f_{A}$ is called approximate function of the soft set $(F, A)$. 
In other words, a soft set over $U$ is a parameterized family of subsets of the universe $U$.

Definition 2.2. ( $[15])$ Let $(F, A)$ and $(F, B)$ be soft sets over $U$.

a) If $f_{A}(x) \subseteq f_{B}(x)$ for all $x \in \mathfrak{X}$, then $(F, A)$ is a soft subset of $(F, B)$, denoted by $(F, A) \widetilde{\subseteq}(F, B)$.

b) If $(F, A) \widetilde{\widetilde{C}}(F, B)$ and $(F, B) \widetilde{\widetilde{\subseteq}}(F, A)$, then the soft sets $(F, A)$ and $(F, B)$ are equal and denoted by $(F, A)=$ $(F, B)$.

c) The soft union of $(F, A)$ and $(F, B)$ is a soft set, denoted by $(F, A) \widetilde{\cup}(F, B)$, and defined as $\left\{\left(x, f_{A}(x) \cup\right.\right.$ $\left.\left.f_{B}(x)\right) \mid x \in \mathfrak{X}, f_{A}(x), f_{B}(x) \in P(U)\right\}$.

d) The soft intersection of $(F, A)$ and $(F, B)$ is a soft set, denoted by $(F, A) \widetilde{\cap}(F, B)$, and defined as $\left\{\left(x, f_{A}(x) \cap\right.\right.$ $\left.\left.f_{B}(x)\right) \mid x \in \mathfrak{X}, f_{A}(x), f_{B}(x) \in P(U)\right\}$.

Definition 2.3. ( [51]) Let $F_{A}$ be a soft set over the universal set $U$. Then, a subset of $U \times \mathfrak{X}$ is uniquely defined as

$$
R_{A}=\left\{\left(\hbar_{i}, x_{j}\right) \mid x_{j} \in A, \hbar_{i} \in F\left(x_{j}\right)\right\}
$$

which is termed to be a relation form of $F_{A}$. The characteristic function of $R_{A}$ is written as follows:

$$
\chi_{R_{A}}: U \times \mathfrak{X} \longrightarrow\{0,1\}, \chi_{R_{A}}\left(\hbar_{i}, x_{j}\right)= \begin{cases}1, & \left(\hbar_{i}, x_{j}\right) \in R_{A} \\ 0, & \left(\hbar_{i}, x_{j}\right) \notin R_{A} .\end{cases}
$$

If $U=\left\{\hbar_{1}, \hbar_{2}, \ldots, \hbar_{m}\right\}, \mathfrak{X}=\left\{x_{1}, x_{2}, \ldots, x_{n}\right\}$ and $A \subseteq \mathfrak{X}$, then $R_{A}$ can be represented by a table as in the following form:

\begin{tabular}{c|cccccc}
$R_{A}$ & $x_{1}$ & $x_{2}$ &. &. &. & $x_{n}$ \\
\hline$\hbar_{1}$ & $\chi_{R_{A}}\left(\hbar_{1}, x_{1}\right)$ & $\chi_{R_{A}}\left(\hbar_{1}, x_{2}\right)$ &. &. &. & $\chi_{R_{A}}\left(u_{1}, x_{n}\right)$ \\
$\hbar_{2}$ & $\chi_{R_{A}}\left(\hbar_{2}, x_{1}\right)$ & $\chi_{R_{A}}\left(\hbar_{2}, x_{2}\right)$ &. &. &. & $\chi_{R_{A}}\left(\hbar_{2}, x_{n}\right)$ \\
$\cdot$ & $\cdot$ & $\cdot$ &. & & $\cdot$ \\
$\cdot$ &. & $\cdot$ & & $\cdot$ & & $\cdot$ \\
$\cdot$ & $\cdot$ & $\cdot$ & & $\cdot$ & $\cdot$ \\
$\hbar_{m}$ & $\chi_{R_{A}}\left(\hbar_{m}, x_{1}\right)$ & $\chi_{R_{A}}\left(\hbar_{m}, x_{2}\right)$ &. &. & $\cdot$ & $\chi_{R_{A}}\left(\hbar_{m}, x_{n}\right)$
\end{tabular}

If $a_{i j}=\chi_{R_{A}}\left(\hbar_{i}, x_{j}\right)$, the matrix

$$
\left[a_{i j}\right]_{m \times n}=\left[\begin{array}{cccccc}
a_{11} & a_{12} & \cdot & \cdot & \cdot & a_{1 n} \\
a_{21} & a_{22} & \cdot & \cdot & \cdot & a_{2 n} \\
\cdot & \cdot & \cdot & & \cdot \\
\cdot & \cdot & & \cdot & \cdot \\
\cdot & \cdot & & \cdot & \cdot \\
a_{m 1} & a_{m 2} & \cdot & \cdot & \cdot & a_{m n}
\end{array}\right] .
$$

is called an $m \times n$ soft matrix of the soft set $F_{A}$ over the universal set $U$. The set of all $m \times n$ soft matrices over $U$ will be denoted by $S M_{m \times n}$. From now on, $\left[a_{i j}\right] \in S M_{m \times n}$ means that $\left[a_{i j}\right]$ is an $m \times n$ soft matrix.

According to the definition of $m \times n$ soft matrix, a soft set $F_{A}$ is uniquely characterized by the matrix $\left[a_{i j}\right]$. It means that a soft set $F_{A}$ is formally equal to its soft matrix $\left[a_{i j}\right][51]$.

Definition 2.4. ([51]) Let $\left[a_{i j}\right],\left[b_{i j}\right] \in S M_{m \times n}$. Then, the soft matrix $\left[c_{i j}\right]$ is called

a) union of $\left[a_{i j}\right]$ and $\left[b_{i j}\right]$, denoted $\left[a_{i j}\right] \widetilde{\cup}\left[b_{i j}\right]$, if $c_{i j}=\max \left\{a_{i j}, b_{i j}\right\}$ for all $i$ and $j$.

b) intersection of $\left[a_{i j}\right]$ and $\left[b_{i j}\right]$, denoted $\left[a_{i j}\right] \widetilde{\cap}\left[b_{i j}\right]$, if $c_{i j}=\min \left\{a_{i j}, b_{i j}\right\}$ for all $i$ and $j$. 
Definition 2.5. ( [52]) Let $\left[a_{i j}\right] \in S M_{m \times n}$ and $\left[b_{i k}\right] \in S M_{m \times n^{\prime}}$. Then, the soft matrix $\left[c_{i p}\right]$ is called

a) generalized And-product of $\left[a_{i j}\right]$ and $\left[b_{i k}\right]$, denoted $\left[a_{i j}\right] \widetilde{\wedge}\left[b_{i j}\right]$, if $c_{i p}=\min \left\{a_{i j}, b_{i k}\right\}$ where $p=(j-1) n^{\prime}+k$.

b) generalized Or-product of $\left[a_{i j}\right]$ and $\left[b_{i k}\right]$, denoted $\left[a_{i j}\right] \widetilde{\mathrm{V}}\left[b_{i j}\right]$, if $c_{i p}=\max \left\{a_{i j}, b_{i k}\right\}$ where $p=(j-1) n^{\prime}+k$.

Theorem 2.6. ([52]) The operation generalized And-product is associative, i.e. if $\left[a_{i j}\right] \in S M_{m \times n_{1}},\left[b_{i k}\right] \in$ $S M_{m \times n_{2}}$ and $\left[c_{i l}\right] \in S M_{m \times n_{3}}$, then

$$
\left(\left[a_{i j}\right] \widetilde{\wedge}\left[b_{i k}\right]\right) \widetilde{\wedge}\left[c_{i l}\right]=\left[a_{i j}\right] \widetilde{\wedge}\left(\left[b_{i k}\right] \widetilde{\wedge}\left[c_{i l}\right]\right) .
$$

\section{Decomposition of soft sets}

In this section, we describe the $\alpha$-intersection and $\alpha$-union of soft sets and provide further theoretical results regarding these new concepts.

Definition 3.1. ( $[21])$ Let $(F, A)$ be soft set over $U$. Then, the set

$$
\operatorname{supp}(F, A)=\left\{x \in A \mid f_{A}(x) \neq \emptyset\right\}
$$

is named the support of the soft set $(F, A)$. The null soft set is a soft set with empty support and denoted by $\emptyset_{\mathfrak{X}}$. A soft set $(F, A)$ is said to be a non-null if $\operatorname{supp}(F, A) \neq \emptyset$.

By the following definition, we can eliminate the elements in which second component is empty set of the soft set.

Definition 3.2. Let $(F, A)$ be soft set over $U$. Then, the soft set $(F, A)_{s}$ defined as

$$
(F, \operatorname{supp}(F, A))=\left\{\left(x, f_{A}(x)\right) \mid x \in \operatorname{supp}(F, A)\right\}
$$

is called the supported soft set of the soft set $(F, A)$.

Now we are ready to define decomposition of soft sets:

Definition 3.3. Let $(F, A)$ be soft set over $U$. If there exist soft sets $(F, B)$ and $(F, C)$ over $U$ such that

a) $\operatorname{supp}(F, A)=\operatorname{supp}(F, B) \cup \operatorname{supp}(F, C)$,

b) $(F, A)_{s}=((F, B) \widetilde{\cup}(F, C))_{s}$,

c) $(F, B) \widetilde{\cap}(F, C)=\emptyset_{\mathfrak{X}}$.

then the soft set $(F, A)$ is said to be a composition of $(F, B)$ and $(F, C)$, and denoted by

$$
(F, A)=(F, B) \oplus(F, C) .
$$

Definition 3.4. ( [20]) Let $(F, A)$ be soft set over $U$ and $\alpha \subseteq U$. Then

a) upper $\alpha$-inclusion of $(F, A)$ is defined as $(F, A) \supseteq \alpha=\left\{x \in A \mid f_{A}(x) \supseteq \alpha\right\}$,

b) lower $\alpha$-inclusion of $(F, A)$ is defined as $(F, A) \subseteq \alpha=\left\{x \in A \mid f_{A}(x) \subseteq \alpha\right\}$.

Theorem 3.5. If $(F, A)=(F, B) \oplus(F, C)$ and $\alpha \subseteq U$, then
i) $(F, A) \frac{\subseteq}{s} \supseteq(F, B) \frac{\subseteq}{s} \cap(F, C) \frac{\subseteq \alpha}{s}$,
ii) $(F, A) \frac{\subseteq}{s} \subseteq(F, B) \frac{\subseteq}{s} \cup(F, C) \frac{\subseteq \alpha}{s}$, 
iii) $(F, A) \stackrel{\supset}{\mathrm{s}} \alpha \supseteq(F, B) \stackrel{\supset}{\mathrm{s}} \alpha \cup(F, C) \stackrel{\supset}{\mathrm{s}} \alpha$.

Proof. i) Let $(F, A)=(F, B) \oplus(F, C)$ and $x \in(F, B) \frac{\subseteq}{s} \cap(F, C) \frac{\subseteq \alpha}{s}$. Then $f_{B}(x) \subseteq \alpha$ and $f_{C}(x) \subseteq \alpha$. Hence $f_{B}(x) \cup f_{C}(x)=f_{A}(x) \subseteq \alpha$. Finally, we have $x \in(F, A) \frac{\subseteq \alpha}{s}$.

ii) Let $x \in(F, A) \frac{\subseteq \alpha}{s}$. Since $f_{A}(x)=f_{B}(x) \cup f_{C}(x)$ and $f_{A}(x) \subseteq \alpha$, we have $f_{B}(x) \subseteq \alpha$ and $f_{C}(x) \subseteq \alpha$. Therefore, $x \in(F, B) \frac{\subseteq}{s} \cup(F, C) \frac{\subseteq}{s}$.

iii) Let $x \in(F, B) \stackrel{\supseteq}{s} \alpha \cup(F, C) \stackrel{\supset}{s}$. Then $f_{B}(x) \supseteq \alpha$ or $f_{C}(x) \supseteq \alpha$ which implies $\left(f_{B}(x) \cup f_{C}(x)\right) \supseteq \alpha$. Since $f_{A}(x)=f_{B}(x) \cup f_{C}(x)$, then $f_{A}(x) \supseteq \alpha$. Hence we have $x \in(F, \bar{A}) \stackrel{\supset}{s}$, which completes the proof.

Example 3.6. Let $U=\left\{\hbar_{1}, \hbar_{2}, \hbar_{3}, \hbar_{4}, \hbar_{5}, \hbar_{6}\right\}$ be a universal discourse set and $\mathfrak{X}=\left\{x_{1}, x_{2}, x_{3}, x_{4}, x_{5}, x_{6}, x_{7}\right\}$ be a set of parameters. Also, $A=\left\{x_{1}, x_{2}, x_{3}, x_{4}, x_{5}\right\}, B=\left\{x_{1}, x_{2}, x_{3}, x_{4}\right\}$ and $C=\left\{x_{1}, x_{2}, x_{3}, x_{4}, x_{5}, x_{6}\right\}$ are three subsets of $\mathfrak{X}$. Suppose that the soft sets related to the parameter subsets $A, B$ and $C$ are

$F_{A}=\left\{\left(x_{1},\left\{\hbar_{1}, \hbar_{2}, \hbar_{3}\right\}\right),\left(x_{2},\left\{\hbar_{1}, \hbar_{4}\right\}\right),\left(x_{3},\left\{\hbar_{2}, \hbar_{3}, \hbar_{5}\right\}\right),\left(x_{4},\left\{\hbar_{1}, \hbar_{5}\right\}\right),\left(x_{5}, \emptyset\right)\right\}$,

$F_{B}=\left\{\left(x_{1},\left\{\hbar_{1}, \hbar_{2}\right\}\right),\left(x_{2}, \emptyset\right),\left(x_{3},\left\{\hbar_{2}\right\}\right),\left(x_{4},\left\{\hbar_{1}\right\}\right)\right\}$

and

$F_{C}=\left\{\left(x_{1},\left\{\hbar_{3}\right\}\right),\left(x_{2},\left\{\hbar_{1}, \hbar_{4}\right\}\right),\left(x_{3},\left\{\hbar_{3}, \hbar_{5}\right\}\right),\left(x_{4},\left\{\hbar_{5}\right\}\right),\left(x_{5}, \emptyset\right),\left(x_{6}, \emptyset\right)\right\}$.

Then, the support sets of these soft sets are

$$
\begin{aligned}
& \operatorname{supp}(F, A)=\left\{x_{1}, x_{2}, x_{3}, x_{4}\right\}, \\
& \operatorname{supp}(F, B)=\left\{x_{1}, x_{3}, x_{4}\right\}, \\
& \operatorname{supp}(F, C)=\left\{x_{1}, x_{2}, x_{3}, x_{4}\right\} .
\end{aligned}
$$

Obviously, we see that

$$
\operatorname{supp}(F, A)=\operatorname{supp}(F, B) \cup \operatorname{supp}(F, C) .
$$

The soft union of $(F, B)$ and $(F, C)$ is the soft set

$(F, B) \widetilde{\cup}(F, C)=\left\{\left(x_{1},\left\{\hbar_{1}, \hbar_{2}, \hbar_{3}\right\}\right),\left(x_{2},\left\{\hbar_{1}, \hbar_{4}\right\}\right),\left(x_{3},\left\{\hbar_{2}, \hbar_{3}, \hbar_{5}\right\}\right),\left(x_{4},\left\{\hbar_{1}, \hbar_{5}\right\}\right),\left(x_{5}, \emptyset\right),\left(x_{6}, \emptyset\right)\right\}$

and the support set of $(F, B) \widetilde{\cup}(F, C)$ is $\operatorname{supp}((F, B) \widetilde{\cup}(F, C))=\left\{x_{1}, x_{2}, x_{3}, x_{4}\right\}$.

Now we can write the soft sets $(F, A)_{s}$ and $((F, B) \widetilde{\cup}(F, C))_{s}$ as follows:

$(F, A)_{s}=\left\{\left(x_{1},\left\{\hbar_{1}, \hbar_{2}, \hbar_{3}\right\}\right),\left(x_{2},\left\{\hbar_{1}, \hbar_{4}\right\}\right),\left(x_{3},\left\{\hbar_{2}, \hbar_{3}, \hbar_{5}\right\}\right),\left(x_{4},\left\{\hbar_{1}, \hbar_{5}\right\}\right)\right\}$

and

$((F, B) \widetilde{\cup}(F, C))_{s}=\left\{\left(x_{1},\left\{\hbar_{1}, \hbar_{2}, \hbar_{3}\right\}\right),\left(x_{2},\left\{\hbar_{1}, \hbar_{4}\right\}\right),\left(x_{3},\left\{\hbar_{2}, \hbar_{3}, \hbar_{5}\right\}\right),\left(x_{4},\left\{\hbar_{1}, \hbar_{5}\right\}\right)\right\}$.

Then, we have

$$
(F, A)_{s}=((F, B) \widetilde{\cup}(F, C))_{s} .
$$

Since

$(F, B) \widetilde{\cap}(F, C)=\left\{\left(x_{1}, \emptyset\right),\left(x_{2}, \emptyset\right),\left(x_{3}, \emptyset\right),\left(x_{4}, \emptyset\right),\left(x_{5}, \emptyset\right),\left(x_{6}, \emptyset\right)\right\}=\emptyset_{\mathfrak{X}}$,

then $(F, A)=(F, B) \oplus(F, C)$. Now let $\alpha=\left\{\hbar_{2}, \hbar_{3}\right\} \subseteq U$. Then 


$$
(F, A) \frac{\subseteq}{s}=\emptyset,(F, B) \frac{\subseteq}{s} \alpha=\left\{x_{3}\right\} \text { and }(F, C) \frac{\subseteq}{s} \alpha=\left\{x_{1}\right\} .
$$

Hence $(F, A) \frac{\subseteq}{s} \supseteq(F, B) \frac{\subseteq}{s} \cap \cap(F, C) \frac{\subseteq}{s}$ and $(F, A) \frac{\subseteq}{s} \subseteq(F, B) \frac{\subseteq \alpha}{s} \cup(F, C) \frac{\subseteq \alpha}{s}$ are satisfied. Now

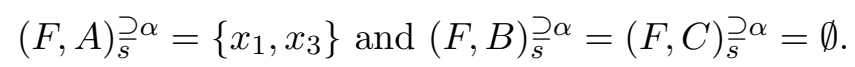

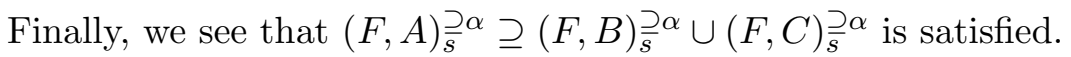

Definition 3.7. Let $(F, A)$ be soft set over $U$ and $\emptyset \neq \alpha \subseteq U$. Then

a) $\alpha$-intersection of $(F, A)$ is defined as $(F, A)^{\cap \alpha}=\left\{x \in A \mid f_{A}(x) \cap \alpha \neq \emptyset\right\}$,

b) $\alpha$-union of $(F, A)$ is defined as $(F, A)^{\cup \alpha}=\left\{x \in A \mid f_{A}(x) \cup \alpha=U\right\}$.

By this definition, it is easily seen that $(F, A)^{\cap \emptyset}=\emptyset,(F, A)^{\cap U}=A,(F, A)^{\cup U}=A$. If $f_{A}(x) \neq U$ for all $x \in A$, then $(F, A)^{\cup \emptyset}=\emptyset$.

Theorem 3.8. If $(F, A)=(F, B) \oplus(F, C)$ and $\emptyset \neq \alpha \subseteq U$, then

i) $(F, B)_{s}^{\cap \alpha} \cup(F, C)_{s}^{\cap \alpha} \subseteq(F, A)_{s}^{\cap \alpha}$,

ii) $(F, B)_{s}^{\cup \alpha} \cup(F, C)_{s}^{\cup \alpha} \subseteq(F, A)_{s}^{\cup \alpha}$,

iii) $(F, B)_{s}^{\cap \alpha} \cap(F, C)_{s}^{\cap \alpha} \subseteq(F, A)_{s}^{\cap \alpha}$.

Proof. i) Let $x \in(F, B)_{s}^{\cap \alpha} \cup(F, C)_{s}^{\cap \alpha}$, then $f_{B}(x) \cap \alpha \neq \emptyset$ or $f_{C}(x) \cap \alpha \neq \emptyset$. Since

$$
f_{A}(x) \cap \alpha=\left(f_{B}(x) \cup f_{C}(x)\right) \cap \alpha=\left(f_{B}(x) \cap \alpha\right) \cup\left(f_{C}(x) \cap \alpha\right),
$$

then $f_{A}(x) \cap \alpha \neq \emptyset$, i.e. $x \in(F, A)_{s}^{\cap \alpha}$ and

$$
(F, B)_{s}^{\cap \alpha} \cup(F, C)_{s}^{\cap \alpha} \subseteq(F, A)_{s}^{\cap \alpha} .
$$

ii) Let $x \in(F, B)_{s}^{\cup \alpha} \cup(F, C)_{s}^{\cup \alpha}$. Then $f_{B}(x) \cap \alpha \neq \emptyset$ or $f_{C}(x) \cap \alpha \neq \emptyset$. Since

$$
f_{A}(x) \cup \alpha=\left(f_{B}(x) \cup f_{C}(x)\right) \cup \alpha=\left(f_{B}(x) \cup \alpha\right) \cup\left(f_{C}(x) \cup \alpha\right)=U,
$$

then $x \in(F, A)_{s}^{\cup \alpha}$. Therefore $(F, B)_{s}^{\cup \alpha} \cup(F, C)_{s}^{\cup \alpha} \subseteq(F, A)_{s}^{\cup \alpha}$ is obtained.

iii) Let $x \in(F, B)_{s}^{\cap \alpha} \cap(F, C)_{s}^{\cap \alpha}$. Then $f_{B}(x) \cap \alpha \neq \emptyset$ and $f_{C}(x) \cap \alpha \neq \emptyset$. Since

$$
f_{A}(x) \cap \alpha=\left(f_{B}(x) \cup f_{C}(x)\right) \cap \alpha \neq \emptyset,
$$

then $x \in(F, A)_{s}^{\cap \alpha}$. Hence $(F, B)_{s}^{\cap \alpha} \cap(F, C)_{s}^{\cap \alpha} \subseteq(F, A)_{s}^{\cap \alpha \alpha}$.

Example 3.9. Let the soft sets $(F, A),(F, B)$ and $(F, C)$ over $U$ given in Example 3.6 and $\alpha=\left\{\hbar_{1}, \hbar_{4}, \hbar_{6}\right\}$. Then

$$
\begin{aligned}
& (F, A)_{s}^{\cap \alpha}=\left\{x_{1}, x_{2}, x_{4}\right\} \text { and }(F, A)_{s}^{\cup \alpha}=\left\{x_{3}\right\}, \\
& (F, B)_{s}^{\cap \alpha}=\left\{x_{1}, x_{4}\right\} \text { and }(F, B)_{s}^{\cup \alpha}=\emptyset, \\
& (F, C)_{s}^{\cap \alpha}=\left\{x_{2}\right\} \text { and }(F, C)_{s}^{\cup \alpha}=\emptyset .
\end{aligned}
$$

Then, we see that the following are satisfied.

$$
\begin{aligned}
& (F, B)_{s}^{\cap \alpha} \cup(F, C)_{s}^{\cap \alpha} \subseteq(F, A)_{s}^{\cap \alpha}, \\
& (F, B)_{s}^{\cup \alpha} \cup(F, C)_{s}^{\cup \alpha} \subseteq(F, A)_{s}^{\cup \alpha}, \\
& (F, B)_{s}^{\cap \alpha} \cap(F, C)_{s}^{\cap \alpha} \subseteq(F, A)_{s}^{\cap \alpha} .
\end{aligned}
$$




\section{Decomposition of soft matrices}

In this section, the support, lower $\alpha$-inclusion, upper $\alpha$-inclusion, $\alpha$-intersection and $\alpha$-union of soft matrices are defined and their remarkable properties are given.

Throughout this section, $U=\left\{\hbar_{1}, \hbar_{2}, \cdots, \hbar_{m}\right\}$ is the universal set, $\mathfrak{X}=\left\{x_{1}, x_{2}, \cdots, x_{n}\right\}$ is the parameter set and $\left[a_{i j}\right] \in S M_{m \times n}$ denotes a soft matrix over $U$.

\section{Notations:}

1. $\left|a_{i j}\right|_{j}$ denotes $j$. column of the soft matrix $\left[a_{i j}\right]$,

2. $|0|_{j}$ means that the $j$. column of $\left[a_{i j}\right]$ consists of zeros,

3. $|1|_{j}$ means that the $j$. column of $\left[a_{i j}\right]$ consists of 1 .

So, we can express a soft matrix $\left[a_{i j}\right]$ as $\bigsqcup_{j=1}^{n}\left|a_{i j}\right|_{j}$ by using its columns.

By the following definition, we give the concept of support set of a soft matrix:

Definition 4.1. Let $\left[a_{i j}\right] \in S M_{m \times n}$. Then the support set of $\left[a_{i j}\right]$ is the subset of $\{1,2, \cdots, n\}$ and defined as

$$
\operatorname{supp}\left[a_{i j}\right]=\left\{j \mid a_{i j} \neq 0, \exists i=1,2, \cdots, m\right\}
$$

Now, we are ready to give the concept "composition of soft matrices".

Definition 4.2. Let $\left[a_{i j}\right] \in S M_{m \times n}$. If there exist soft matrices $\left[b_{i j}\right],\left[c_{i j}\right] \in S M_{m \times n}$ such that,

a) $\operatorname{supp}\left[a_{i j}\right]=\operatorname{supp}\left[b_{i j}\right] \cup \operatorname{supp}\left[c_{i j}\right]$,

b) $\left[a_{i j}\right]=\left[b_{i j}\right] \widetilde{\cup}\left[c_{i j}\right]$,

c) $\left[b_{i j}\right] \widetilde{\cap}\left[c_{i j}\right]=[0]$

then the soft matrix $\left[a_{i j}\right]$ is said to be a composition of $\left[b_{i j}\right]$ and $\left[c_{i j}\right]$, and denoted by

$$
\left[a_{i j}\right]=\left[b_{i j}\right] \oplus\left[c_{i j}\right]
$$

Example 4.3. We consider the soft sets $(F, A),(F, B)$ and $(F, C)$ given in Example 3.6. Then, the corresponding soft matrices of soft sets $(F, A),(F, B)$ and $(F, C)$ over $U$ are respectively

$$
\left[a_{i j}\right]=\left[\begin{array}{ccccccc}
1 & 1 & 0 & 1 & 0 & 0 & 0 \\
1 & 0 & 1 & 0 & 0 & 0 & 0 \\
1 & 0 & 1 & 0 & 0 & 0 & 0 \\
0 & 1 & 0 & 0 & 0 & 0 & 0 \\
0 & 0 & 1 & 1 & 0 & 0 & 0 \\
0 & 0 & 0 & 0 & 0 & 0 & 0
\end{array}\right],\left[b_{i j}\right]=\left[\begin{array}{ccccccc}
1 & 0 & 0 & 1 & 0 & 0 & 0 \\
1 & 0 & 1 & 0 & 0 & 0 & 0 \\
0 & 0 & 0 & 0 & 0 & 0 & 0 \\
0 & 0 & 0 & 0 & 0 & 0 & 0 \\
0 & 0 & 0 & 0 & 0 & 0 & 0 \\
0 & 0 & 0 & 0 & 0 & 0 & 0
\end{array}\right] \text { and }\left[c_{i j}\right]=\left[\begin{array}{ccccccc}
0 & 1 & 0 & 0 & 0 & 0 & 0 \\
0 & 0 & 0 & 0 & 0 & 0 & 0 \\
1 & 0 & 1 & 0 & 0 & 0 & 0 \\
0 & 1 & 0 & 0 & 0 & 0 & 0 \\
0 & 0 & 1 & 1 & 0 & 0 & 0 \\
0 & 0 & 0 & 0 & 0 & 0 & 0
\end{array}\right] .
$$

Then,

$$
\operatorname{supp}\left[a_{i j}\right]=\{1,2,3,4\}, \operatorname{supp}\left[b_{i j}\right]=\{1,3,4\} \text { and } \operatorname{supp}\left[c_{i j}\right]=\{1,2,3,4\} .
$$

It is seen that

$$
\operatorname{supp}\left[a_{i j}\right]=\operatorname{supp}\left[b_{i j}\right] \cup \operatorname{supp}\left[c_{i j}\right],\left[a_{i j}\right]=\left[b_{i j}\right] \widetilde{\cup}\left[c_{i j}\right] \text { and }\left[b_{i j}\right] \widetilde{\cap}\left[c_{i j}\right]=[0]
$$

are satisfied. Hence, we have $\left[a_{i j}\right]=\left[b_{i j}\right] \oplus\left[c_{i j}\right]$. 
We can express a soft set $(F, A)$ over $U$ by its soft matrix, mutually. Following theorem shows that this is valid for composition of soft sets and composition of soft matrices.

Theorem 4.4. Let $(F, A),(F, B)$ and $(F, C)$ be soft sets over $U$ and let $\left[a_{i j}\right],\left[b_{i j}\right]$ and $\left[c_{i j}\right]$ be corresponding soft matrices, respectively. Then

$$
(F, A)=(F, B) \oplus(F, C) \text { if and only if }\left[a_{i j}\right]=\left[b_{i j}\right] \oplus\left[c_{i j}\right]
$$

Proof. Let $(F, A)=(F, B) \oplus(F, C)$. By the definitions of $\operatorname{supp}(F, A)$ and $\operatorname{supp}\left[a_{i j}\right]$, it is seen that

$$
x_{j} \in \operatorname{supp}(F, A) \text { if and only if } j \in \operatorname{supp}\left[a_{i j}\right] .
$$

Then $\operatorname{supp}(F, A)=\operatorname{supp}(F, B) \cup \operatorname{supp}(F, C)$ iff $\operatorname{supp}\left[a_{i j}\right]=\operatorname{supp}\left[b_{i j}\right] \cup \operatorname{supp}\left[c_{i j}\right]$.

Assume that $R_{A}, R_{B}$ and $R_{C}$ are relation forms of the $\operatorname{soft} \operatorname{sets}(F, A),(F, B)$ and $(F, C)$, respectively.

By Definitions 2.3 and 2.4,

$\left(\hbar_{i}, x_{j}\right) \in R_{A}$ implies that $\left(\hbar_{i}, x_{j}\right) \in R_{B}$ or $\left(\hbar_{i}, x_{j}\right) \in R_{C}$ if and only if

$a_{i j}=\chi_{R_{A}}\left(\hbar_{i}, x_{j}\right)=\max \left\{b_{i j}=\chi_{R_{B}}\left(\hbar_{i}, x_{j}\right), c_{i j}=\chi_{R_{C}}\left(\hbar_{i}, x_{j}\right)\right\}$

and

$\left(\hbar_{i}, x_{j}\right) \in R_{B}$ and $\left(\hbar_{i}, x_{j}\right) \in R_{C}$ if and only if $\min \left\{b_{i j}=\chi_{R_{B}}\left(\hbar_{i}, x_{j}\right), c_{i j}=\chi_{R_{C}}\left(\hbar_{i}, x_{j}\right)\right\}=1$

Then

$$
(F, A)_{s}=((F, B) \widetilde{\cup}(F, C))_{s} \text { if and only if }\left[a_{i j}\right]=\left[b_{i j}\right] \widetilde{\cup}\left[c_{i j}\right]
$$

and

$$
(F, B) \widetilde{\cap}(F, C)=\emptyset_{\mathfrak{X}} \text { if and only if }\left[b_{i j}\right] \widetilde{\cap}\left[c_{i j}\right]=[0] .
$$

Therefore, by considering Definitions 3.3 and 4.2 , we have

$$
(F, A)=(F, B) \oplus(F, C) \text { if and only if }\left[a_{i j}\right]=\left[b_{i j}\right] \oplus\left[c_{i j}\right] .
$$

Definition 4.5. Let $\left[a_{i j}\right] \in S M_{m \times n}$ and let $\alpha=\left\{\hbar_{i} \mid i \in I\right\} \subseteq U$, where $I \subseteq\{1,2, \cdots, m\}$. Then,

a) $\alpha$-upper soft matrix of $\left[a_{i j}\right]$ denoted by $\left[a_{i j}\right]^{\alpha}$ is defined as,

$$
\left[a_{i j}\right]^{\alpha}=\bigsqcup_{j=1}^{n} \begin{cases}\left|a_{i j}\right|_{j}, & \text { if } \forall i \in I, a_{i j}=1 \\ |0|_{j}, & \text { otherwise }\end{cases}
$$

b) $\alpha$-lower soft matrix of $\left[a_{i j}\right]$ denoted by $\left[a_{i j}\right]_{\alpha}$ is defined as,

$$
\left[a_{i j}\right]_{\alpha}=\bigsqcup_{j=1}^{n} \begin{cases}|0|_{j}, & \text { if } \forall i \in\{1,2, \cdots, m\} \backslash I, a_{i j}=1 \\ \left|a_{i j}\right|_{j}, & \text { otherwise }\end{cases}
$$

It is clear that $\left[a_{i j}\right]^{\alpha}$ and $\left[a_{i j}\right]_{\alpha}$ are also $m \times n$ soft matrices.

Example 4.6. We consider the soft matrix $\left[a_{i j}\right]$ given in Example 4.3 and $\alpha=\left\{\hbar_{5}\right\}$. Then $I=\{5\}$ and

$$
\left[a_{i j}\right]^{\alpha}=\left[\begin{array}{ccccccc}
0 & 0 & 0 & 1 & 0 & 0 & 0 \\
0 & 0 & 1 & 0 & 0 & 0 & 0 \\
0 & 0 & 1 & 0 & 0 & 0 & 0 \\
0 & 0 & 0 & 0 & 0 & 0 & 0 \\
0 & 0 & 1 & 1 & 0 & 0 & 0 \\
0 & 0 & 0 & 0 & 0 & 0 & 0
\end{array}\right]
$$


Now let $\beta=\left\{\hbar_{1}, \hbar_{2}, \hbar_{3}, \hbar_{5}\right\}$. Then $I=\{1,2,3,5\}$ and

$$
\left[a_{i j}\right]_{\beta}=\left[\begin{array}{ccccccc}
1 & 0 & 0 & 1 & 0 & 0 & 0 \\
1 & 0 & 1 & 0 & 0 & 0 & 0 \\
1 & 0 & 1 & 0 & 0 & 0 & 0 \\
0 & 0 & 0 & 0 & 0 & 0 & 0 \\
0 & 0 & 1 & 1 & 0 & 0 & 0 \\
0 & 0 & 0 & 0 & 0 & 0 & 0
\end{array}\right]
$$

Theorem 4.7. Let $(F, A)$ be a soft set over $U=\left\{\hbar_{1}, \hbar_{2}, \cdots, \hbar_{m}\right\}, \emptyset \neq \alpha \subseteq U$ and let $\left[a_{i j}\right]$ be the soft matrix of $(F, A)$. Then

i) $\left[a_{i j}\right]^{\alpha}$ is the soft matrix of the soft set $(F,(F, A) \supseteq \alpha)$.

ii) $\left[a_{i j}\right]_{\alpha}$ is the soft matrix of the soft $\operatorname{set}(F,(F, A) \subseteq \alpha)$.

Proof. Let $\alpha=\left\{\hbar_{i} \mid i \in I\right\}$, where $\emptyset \neq I \subseteq\{1,2, \cdots, m\}$.

i) Since

$$
(F, A) \supseteq \alpha=\left\{x_{j} \in A \mid f_{A}\left(x_{j}\right) \supseteq \alpha\right\},
$$

then $\hbar_{i} \in \alpha$ implies that $\left(\hbar_{i}, x_{j}\right) \in R_{A^{\alpha}}$, where $R_{A^{\alpha}}$ is the relation form of the soft set $(F,(F, A) \supseteq \alpha)$. If $\hbar_{i} \in \alpha$, then $\chi_{R_{A^{\alpha}}}\left(\hbar_{i}, x_{j}\right)=a_{i j}$, which is the $i j$-th component of $\left[a_{i j}\right]^{\alpha}$.

ii) Since

$$
(F, A) \subseteq \alpha=\left\{x_{j} \in A \mid f_{A}\left(x_{j}\right) \subseteq \alpha\right\},
$$

then $\left(\hbar_{i}, x_{j}\right) \in R_{A_{\alpha}}$, where $R_{A_{\alpha}}$ is the relation form of the soft set $(F,(F, A) \subseteq \alpha)$. That's mean, if $\hbar_{i} \in U \backslash \alpha$, then $\chi_{R_{A_{\alpha}}}\left(\hbar_{i}, x_{j}\right)=0$. Hence the proof is seen by Definition 4.5.

Corollary 4.8. Let $\left[a_{i j}\right] \in S M_{m \times n}$ and let $\alpha=\left\{\hbar_{i} \mid i \in I\right\}$, where $\emptyset \neq I \subseteq\{1,2, \cdots, m\}$. If $\left[a_{i j}\right]=\left[b_{i j}\right] \oplus\left[c_{i j}\right]$, then
i) $\left[a_{i j}\right]^{\alpha} \supseteq\left[b_{i j}\right]^{\alpha} \widetilde{\cap}\left[c_{i j}\right]^{\alpha}$.
ii) $\left[a_{i j}\right]^{\alpha} \supseteq\left[b_{i j}\right]^{\alpha} \widetilde{\cup}\left[c_{i j}\right]^{\alpha}$.
iii) $\left[a_{i j}\right]_{\alpha} \subseteq\left[b_{i j}\right]_{\alpha} \widetilde{\cup}\left[c_{i j}\right]_{\alpha}$.

Proof. The proofs are seen by Theorems 3.5, 4.4 and 4.7 .

Example 4.9. Consider the soft matrices $\left[a_{i j}\right],\left[b_{i j}\right]$ and $\left[c_{i j}\right]$ given in Example 4.3 and assume $\alpha=\left\{\hbar_{3}, \hbar_{5}\right\}$. Then $I=\{3,5\}$ and $\left[a_{i j}\right]^{\alpha}=\left[\begin{array}{ccccccc}0 & 0 & 0 & 0 & 0 & 0 & 0 \\ 0 & 0 & 1 & 0 & 0 & 0 & 0 \\ 0 & 0 & 1 & 0 & 0 & 0 & 0 \\ 0 & 0 & 0 & 0 & 0 & 0 & 0 \\ 0 & 0 & 1 & 0 & 0 & 0 & 0 \\ 0 & 0 & 0 & 0 & 0 & 0 & 0\end{array}\right],\left[b_{i j}\right]^{\alpha}=[0]$ and $\left[c_{i j}\right]^{\alpha}=\left[\begin{array}{ccccccc}0 & 0 & 0 & 0 & 0 & 0 & 0 \\ 0 & 0 & 0 & 0 & 0 & 0 & 0 \\ 0 & 0 & 1 & 0 & 0 & 0 & 0 \\ 0 & 0 & 0 & 0 & 0 & 0 & 0 \\ 0 & 0 & 1 & 0 & 0 & 0 & 0 \\ 0 & 0 & 0 & 0 & 0 & 0 & 0\end{array}\right]$.

Moreover, we obtain 
$\left[a_{i j}\right]_{\alpha}=[0],\left[b_{i j}\right]_{\alpha}=[0]$, and $\left[c_{i j}\right]_{\alpha}=\left[\begin{array}{ccccccc}0 & 0 & 0 & 0 & 0 & 0 & 0 \\ 0 & 0 & 0 & 0 & 0 & 0 & 0 \\ 1 & 0 & 1 & 0 & 0 & 0 & 0 \\ 0 & 0 & 0 & 0 & 0 & 0 & 0 \\ 0 & 0 & 1 & 0 & 0 & 0 & 0 \\ 0 & 0 & 0 & 0 & 0 & 0 & 0\end{array}\right]$.

Then it is seen that $\left[a_{i j}\right]^{\alpha} \supseteq\left[b_{i j}\right]^{\alpha} \widetilde{\cap}\left[c_{i j}\right]^{\alpha},\left[a_{i j}\right]^{\alpha} \supseteq\left[b_{i j}\right]^{\alpha} \widetilde{\cup}\left[c_{i j}\right]^{\alpha}$ and $\left[a_{i j}\right]_{\alpha} \subseteq\left[b_{i j}\right]_{\alpha} \widetilde{\cup}\left[c_{i j}\right]_{\alpha}$ are satisfied.

Definition 4.10. Let $\left[a_{i j}\right] \in S M_{m \times n}$ and let $\alpha=\left\{\hbar_{i} \mid i \in I\right\} \subseteq U$, where $I \subseteq\{1,2, \cdots, m\}$. Then,

a) $\alpha$-intersection soft matrix of $\left[a_{i j}\right]$ denoted by $\left[a_{i j}\right]^{\cap \alpha}$ is defined as,

$$
\left[a_{i j}\right]^{\cap \alpha}=\bigsqcup_{j=1}^{n} \begin{cases}\left|a_{i j}\right|_{j}, & \text { if } \exists i \in I, a_{i j}=1 \\ |0|_{j}, & \text { otherwise }\end{cases}
$$

b) $\alpha$-union soft matrix of $\left[a_{i j}\right]$ denoted by $\left[a_{i j}\right]^{\cup \alpha}$ is defined as,

$$
\left[a_{i j}\right]^{\cup \alpha}=\bigsqcup_{j=1}^{n} \begin{cases}\left|a_{i j}\right|_{j}, & \text { if } \forall i \in\{1,2, \cdots, m\} \backslash I, a_{i j}=1 \\ |0|_{j}, & \text { otherwise }\end{cases}
$$

It is clear that $\left[a_{i j}\right]^{\cap \alpha}$ and $\left[a_{i j}\right]^{\cup \alpha}$ are also $m \times n$ soft matrices.

Theorem 4.11. Let $(F, A)$ be a soft set over $U=\left\{\hbar_{1}, \hbar_{2}, \cdots, \hbar_{m}\right\}, \emptyset \neq \alpha \subseteq U$ and let $\left[a_{i j}\right]$ be the soft matrix of $(F, A)$. Then

i) $\left[a_{i j}\right]^{\cap \alpha}$ is the soft matrix of the soft set $\left(F,(F, A)^{\cap \alpha}\right)$.

ii) $\left[a_{i j}\right]^{\cup \alpha}$ is the soft matrix of the soft set $\left(F,(F, A)^{\cup \alpha}\right)$.

Proof. Let $\alpha=\left\{\hbar_{i} \mid i \in I\right\}$, where $\emptyset \neq I \subseteq\{1,2, \cdots, m\}$.

i) Since

$$
(F, A)^{\cap \alpha}=\left\{x_{j} \in A \mid f_{A}\left(x_{j}\right) \cap \alpha \neq \emptyset\right\},
$$

then $\hbar_{i} \in f_{A}\left(x_{j}\right) \cap \alpha$ implies that $\left(\hbar_{i}, x_{j}\right) \in R_{A \cap \alpha}$, where $R_{A \cap \alpha}$ is the relation form of the soft set $\left(F,(F, A)^{\cap \alpha}\right)$. That's mean, if $\hbar_{i} \in f_{A}\left(x_{j}\right) \cap \alpha$, then $\chi_{R_{A} \cap \alpha}\left(\hbar_{i}, x_{j}\right)=a_{i j}$, which is the $i j$-th component of $\left[a_{i j}\right]^{\cap \alpha}$.

ii) Let $R_{A \cup \alpha}$ is the relation form of the soft set $\left(F,(F, A)^{\cup \alpha}\right)$. Since

$$
(F, A)^{\cup \alpha}=\left\{x_{j} \in A \mid f_{A}\left(x_{j}\right) \cup \alpha=U\right\},
$$

then $\left(\hbar_{i}, x_{j}\right) \in R_{A \cup \alpha}$ implies that for $\exists i \in\{1,2, \cdots, m\} \backslash I, \chi_{R_{A} \cup \alpha}\left(\hbar_{i}, x_{j}\right)=a_{i j}$, which is the $i j$-th component of $\left[a_{i j}\right]^{\cup \alpha}$. Hence the proof is seen by Definition 4.10.

Corollary 4.12. Let $\left[a_{i j}\right] \in S M_{m \times n}$ and let $\alpha=\left\{\hbar_{i} \mid i \in I\right\}$, where $\emptyset \neq I \subseteq\{1,2, \cdots, m\}$. If $\left[a_{i j}\right]=\left[b_{i j}\right] \oplus\left[c_{i j}\right]$, then
i) $\left[a_{i j}\right]^{\cap \alpha} \supseteq\left[b_{i j}\right]^{\cap \alpha} \widetilde{\cup}\left[c_{i j}\right]^{\cap \alpha}$.
ii) $\left[a_{i j}\right]^{\cap \alpha} \supseteq\left[b_{i j}\right]^{\cap \alpha} \widetilde{\cap}\left[c_{i j}\right]^{\cap \alpha}$.
iii) $\left[a_{i j}\right]^{\cup \alpha} \supseteq\left[b_{i j}\right]^{\cup \alpha} \widetilde{\cup}\left[c_{i j}\right]^{\cup \alpha}$.

Proof. The proof is seen by Theorems 3.8, 4.4 and 4.11 . 
Example 4.13. We take the soft matrices $\left[a_{i j}\right],\left[b_{i j}\right]$ and $\left[c_{i j}\right]$ given in Example 4.3 and $\alpha=\left\{\hbar_{3}, \hbar_{4}, \hbar_{5}, \hbar_{6}\right\}$. Then $I=\{3,4,5,6\}$ and

$\left[a_{i j}\right]^{\cap \alpha}=\left[\begin{array}{ccccccc}1 & 1 & 0 & 1 & 0 & 0 & 0 \\ 1 & 0 & 1 & 0 & 0 & 0 & 0 \\ 1 & 0 & 1 & 0 & 0 & 0 & 0 \\ 0 & 1 & 0 & 0 & 0 & 0 & 0 \\ 0 & 0 & 1 & 1 & 0 & 0 & 0 \\ 0 & 0 & 0 & 0 & 0 & 0 & 0\end{array}\right]=\left[a_{i j}\right],\left[b_{i j}\right]^{\cap \alpha}=[0]$ and $\left[c_{i j}\right]^{\cap \alpha}=\left[\begin{array}{ccccccc}0 & 1 & 0 & 0 & 0 & 0 & 0 \\ 0 & 0 & 0 & 0 & 0 & 0 & 0 \\ 1 & 0 & 1 & 0 & 0 & 0 & 0 \\ 0 & 1 & 0 & 0 & 0 & 0 & 0 \\ 0 & 0 & 1 & 1 & 0 & 0 & 0 \\ 0 & 0 & 0 & 0 & 0 & 0 & 0\end{array}\right]=\left[c_{i j}\right]$.

Moreover, we obtain

$\left[a_{i j}\right]^{\cup \alpha}=\left[\begin{array}{ccccccc}1 & 0 & 0 & 0 & 0 & 0 & 0 \\ 1 & 0 & 0 & 0 & 0 & 0 & 0 \\ 1 & 0 & 0 & 0 & 0 & 0 & 0 \\ 0 & 0 & 0 & 0 & 0 & 0 & 0 \\ 0 & 0 & 0 & 0 & 0 & 0 & 0 \\ 0 & 0 & 0 & 0 & 0 & 0 & 0\end{array}\right],\left[b_{i j}\right]^{\cup \alpha}=\left[\begin{array}{ccccccc}1 & 0 & 0 & 0 & 0 & 0 & 0 \\ 1 & 0 & 0 & 0 & 0 & 0 & 0 \\ 0 & 0 & 0 & 0 & 0 & 0 & 0 \\ 0 & 0 & 0 & 0 & 0 & 0 & 0 \\ 0 & 0 & 0 & 0 & 0 & 0 & 0 \\ 0 & 0 & 0 & 0 & 0 & 0 & 0\end{array}\right]$ and $\left[c_{i j}\right]^{\cup \alpha}=[0]$.

Then, it is seen that $\left[a_{i j}\right]^{\cap \alpha} \supseteq\left[b_{i j}\right]^{\cap \alpha} \widetilde{\cup}\left[c_{i j}\right]^{\cap \alpha},\left[a_{i j}\right]^{\cap \alpha} \supseteq\left[b_{i j}\right]^{\cap \alpha} \widetilde{\cap}\left[c_{i j}\right]^{\cap \alpha}$ and $\left[a_{i j}\right]^{\cup \alpha} \supseteq\left[b_{i j}\right]^{\cup \alpha} \widetilde{\cup}\left[c_{i j}\right]^{\cup \alpha}$ are satisfied.

\section{Set-Restricted Soft Decision Making}

In this section, we define the concepts of aggregate-row function, aggregate decision triple, first and second decision values. By using these concepts, we construct two soft decision making algorithms, the first of which is to deal with classical group decision making problems and the other is to deal with set-restricted group decision making problems.

Definition 5.1. Let $\left[a_{i j}\right] \in S M_{m \times n}$. Then aggregate-row function, denoted by $\tau_{i}$, is defined by

$$
\tau_{i}: S M_{m \times n} \rightarrow \mathbb{Z}, \tau_{i}\left(\left[a_{i j}\right]\right)=\sum_{j=1}^{n} a_{i j}
$$

for $i \in\{1,2, \ldots, m\}$.

Definition 5.2. Let $\left[a_{i j}^{1}\right],\left[a_{i j}^{2}\right], \ldots,\left[a_{i j}^{r}\right] \in S M_{m \times n}$. Also let $\left[c_{i p}\right]=\widetilde{\wedge}_{t=1}^{r}\left[a_{i j}^{t}\right]$ and $\left[d_{i j}\right]=\widetilde{\cap}_{t=1}^{r}\left[a_{i j}^{t}\right]$. Then, the triple

$$
\kappa_{i}=\left(\kappa_{i}^{1}, \kappa_{i}^{2}, \kappa_{i}^{3}\right)
$$

is called an aggregate decision triple of $h_{i} \in U$, where the decision components $\kappa_{i}^{1}, \kappa_{i}^{2}$ and $\kappa_{i}^{3}$ are calculated as below:

$\kappa_{i}^{1}=\tau_{i}\left(\left[c_{i p}\right]\right), \kappa_{i}^{2}=\sum_{t=1}^{r} \tau_{i}\left(\left[a_{i j}^{t}\right]\right)$ and $\kappa_{i}^{3}=r \times \tau_{i}\left(\left[d_{i j}\right]\right)$.

Definition 5.3. Let $\kappa_{i}=\left(\kappa_{i}^{1}, \kappa_{i}^{2}, \kappa_{i}^{3}\right)$ be an aggregate decision triple of $\hbar_{i} \in U$. Then,

a) the value $\ell_{i}^{1}=\kappa_{i}^{1}+\kappa_{i}^{2}$ is called a first decision value for $\hbar_{i} \in U$,

b) the value $\ell_{i}^{2}=2 \kappa_{i}^{3}-\kappa_{i}^{2}$ is called a second decision value for $\hbar_{i} \in U$.

For $h_{i}, h_{i}^{\prime} \in U$, the selection order of $\kappa_{i}$ and $\kappa_{i}^{\prime}$ is found as follows:

- If $\ell_{i}^{1}>\ell_{i^{\prime}}^{1}$ then we have $\kappa_{i}>\kappa_{i}^{\prime}$.

- If $\ell_{i}^{1}=\ell_{i^{\prime}}^{1}$, we consider the second decision values $\ell^{2}$. 
- If $\ell_{i}^{2}>\ell_{i^{\prime}}^{2}$ then we have $\kappa_{i}>\kappa_{i}^{\prime}$.

- If $\ell_{i}^{1}=\ell_{i^{\prime}}^{1}$ and $\ell_{i}^{2}=\ell_{i^{\prime}}^{2}$, we have $\kappa_{i}=\kappa_{i}^{\prime}$.

Definition 5.4. Let $U=\left\{\hbar_{1}, \hbar_{2}, \ldots, \hbar_{m}\right\}$ be a universal set. By using the aggregate decision triple $\kappa_{i}$, the first decision value $\ell_{i}^{1}$ and the second decision value $\ell_{i}^{2}$, we find the ranking order of objects as follows:

$$
\hbar_{i_{1}} \succ \hbar_{i_{1}} \succ \ldots \succ \hbar_{i_{m}} \text { if } \kappa_{i_{1}}>\kappa_{i_{2}}>\ldots>\kappa_{i_{m}} .
$$

Then, we obtain a subset of $U$ as follows:

$$
O p t_{\kappa}(U)=\left\{\hbar_{i}: \hbar_{i} \in U \text { and } \kappa_{\mathrm{i}}>\kappa_{\mathrm{i}^{\prime}} \text { for each } \mathrm{i}^{\prime} \neq \mathrm{i}\right\}
$$

which is called an optimum set of $U$.

By using the emerged notions in the soft matrix theory, let us create an algorithm for group decision making.

Algorithm 1. (Soft Decision Making Algorithm)

Step 1. Decision makers (DMs) choose feasible subsets of the parameter set and then create soft sets.

Step 2. Construct the soft matrices $\left[a_{i j}^{1}\right],\left[a_{i j}^{2}\right], \ldots,\left[a_{i j}^{r}\right]$.

Step 3. Obtain the soft matrices $\left[c_{i p}\right]=\widetilde{\wedge}_{t=1}^{r}\left[a_{i j}^{t}\right]$ and $\left[d_{i j}\right]=\widetilde{\cap}_{t=1}^{r}\left[a_{i j}^{t}\right]$.

Step 4. Find the aggregate decision triple $\kappa_{i}=\left(\kappa_{i}^{1}, \kappa_{i}^{2}, \kappa_{i}^{3}\right)$ for $i=1,2, \ldots, m$.

Step 5. Obtain the ranking order of objects $h_{i} \in U(i=1,2, \ldots, m)$ and find the optimum set of $U$.

The step by step procedure of Algorithm 1 (Soft Decision Making Algorithm) is illustrated in Figure 1.

\section{[Insert Figure 1]}

Now, we present an illustrative example for the Algorithm 1.

Example 5.5. Mr. X, Mrs. X and daughter X are moving into a big city. They are planning to buy a house in this city, so they set the criteria they want. Their common criteria are $x_{1}=$ Budget-friendly, $x_{2}=$ Modern and $x_{3}=$ Beautiful designed. The real estate agent offers them nine houses $U=\left\{\hbar_{1}, \hbar_{2}, \cdots, \hbar_{9}\right\}$ that carry some of these criteria.

Step 1. By determining the houses that correspond for each of their criteria, they created the following soft sets as follows, respectively:

$F_{A_{1}}=\left\{\left(x_{1},\left\{\hbar_{3}, \hbar_{6}, \hbar_{7}\right\}\right),\left(x_{2},\left\{\hbar_{1}, \hbar_{2}, \hbar_{4}, \hbar_{5}, \hbar_{7}\right\}\right),\left(x_{3},\left\{\hbar_{1}, \hbar_{3}, \hbar_{4}, \hbar_{6}, \hbar_{7}, \hbar_{8}\right\}\right)\right\}$,

$F_{A_{2}}=\left\{\left(x_{1},\left\{\hbar_{1}, \hbar_{3}, \hbar_{7}, \hbar_{9}\right\}\right),\left(x_{2},\left\{\hbar_{2}, \hbar_{4}, \hbar_{5}, \hbar_{7}, \hbar_{8}, \hbar_{9}\right\}\right),\left(x_{3},\left\{\hbar_{3}, \hbar_{4}, \hbar_{6}, \hbar_{9}\right\}\right)\right\}$,

$F_{A_{3}}=\left\{\left(x_{2},\left\{\hbar_{2}, \hbar_{3}, \hbar_{4}, \hbar_{5}, \hbar_{6}, \hbar_{7}, \hbar_{9}\right\}\right),\left(x_{3},\left\{\hbar_{3}, \hbar_{5}, \hbar_{6}, \hbar_{9}\right\}\right)\right\}$.

Step 2. The soft matrices of soft sets $F_{A_{1}}, F_{A_{2}}$ and $F_{A_{3}}$ are respectively

$$
\left[a_{i j}^{1}\right]=\left[\begin{array}{ccc}
0 & 1 & 1 \\
0 & 1 & 0 \\
1 & 0 & 1 \\
0 & 1 & 1 \\
0 & 1 & 0 \\
1 & 0 & 1 \\
1 & 1 & 1 \\
0 & 0 & 1 \\
0 & 0 & 0
\end{array}\right],\left[a_{i j}^{2}\right]=\left[\begin{array}{ccc}
1 & 0 & 0 \\
0 & 1 & 0 \\
1 & 0 & 1 \\
0 & 1 & 1 \\
0 & 1 & 0 \\
0 & 0 & 1 \\
1 & 1 & 0 \\
0 & 1 & 0 \\
1 & 1 & 1
\end{array}\right] \text { and }\left[a_{i j}^{3}\right]=\left[\begin{array}{ccc}
0 & 0 & 0 \\
0 & 1 & 0 \\
0 & 1 & 1 \\
0 & 1 & 0 \\
0 & 1 & 1 \\
0 & 1 & 1 \\
0 & 1 & 0 \\
0 & 0 & 0 \\
0 & 1 & 1
\end{array}\right] .
$$


Step 3. They obtain the soft matrices

$\left[c_{i p}\right]=\sim_{t=1}^{3}\left[a_{i j}^{t}\right]=\left[\begin{array}{lllllllllllllllllllllllllll}0 & 0 & 0 & 0 & 0 & 0 & 0 & 0 & 0 & 0 & 0 & 0 & 0 & 0 & 0 & 0 & 0 & 0 & 0 & 0 & 0 & 0 & 0 & 0 & 0 & 0 & 0 \\ 0 & 0 & 0 & 0 & 0 & 0 & 0 & 0 & 0 & 0 & 0 & 0 & 0 & 1 & 0 & 0 & 0 & 0 & 0 & 0 & 0 & 0 & 0 & 0 & 0 & 0 & 0 \\ 0 & 1 & 1 & 0 & 0 & 0 & 0 & 1 & 1 & 0 & 0 & 0 & 0 & 0 & 0 & 0 & 0 & 0 & 0 & 1 & 1 & 0 & 0 & 0 & 0 & 1 & 1 \\ 0 & 0 & 0 & 0 & 0 & 0 & 0 & 0 & 0 & 0 & 0 & 0 & 0 & 1 & 0 & 0 & 1 & 0 & 0 & 0 & 0 & 0 & 1 & 0 & 0 & 1 & 0 \\ 0 & 0 & 0 & 0 & 0 & 0 & 0 & 0 & 0 & 0 & 0 & 0 & 0 & 1 & 1 & 0 & 0 & 0 & 0 & 0 & 0 & 0 & 0 & 0 & 0 & 0 & 0 \\ 0 & 0 & 0 & 0 & 0 & 0 & 0 & 1 & 1 & 0 & 0 & 0 & 0 & 0 & 0 & 0 & 0 & 0 & 0 & 0 & 0 & 0 & 0 & 0 & 0 & 1 & 1 \\ 0 & 1 & 0 & 0 & 1 & 0 & 0 & 0 & 0 & 0 & 1 & 0 & 0 & 1 & 0 & 0 & 0 & 0 & 0 & 1 & 0 & 0 & 1 & 0 & 0 & 0 & 0 \\ 0 & 0 & 0 & 0 & 0 & 0 & 0 & 0 & 0 & 0 & 0 & 0 & 0 & 0 & 0 & 0 & 0 & 0 & 0 & 0 & 0 & 0 & 0 & 0 & 0 & 0 & 0 \\ 0 & 0 & 0 & 0 & 0 & 0 & 0 & 0 & 0 & 0 & 0 & 0 & 0 & 0 & 0 & 0 & 0 & 0 & 0 & 0 & 0 & 0 & 0 & 0 & 0 & 0 & 0\end{array}\right]$

and

$$
\left[d_{i j}\right]=\widetilde{\cap}_{t=1}^{3}\left[a_{i j}^{t}\right]=\left[\begin{array}{lll}
0 & 0 & 0 \\
0 & 1 & 0 \\
0 & 0 & 1 \\
0 & 1 & 0 \\
0 & 1 & 0 \\
0 & 0 & 1 \\
0 & 1 & 0 \\
0 & 0 & 0 \\
0 & 0 & 0
\end{array}\right]
$$

Step 4. The aggregate decision triple for each $i=1,2, \ldots, 9$ is calculated as in Table 1 .

\section{[Insert Table 1]}

Figure 2 gives a graphical representation of aggregate decision triples in Table 1.

\section{[Insert Figure 2]}

Step 5. Then, the ranking order of houses is obtained as

$$
\hbar_{3} \succ \hbar_{7} \succ \hbar_{4}=\hbar_{6} \succ \hbar_{5} \succ \hbar_{9} \succ \hbar_{2} \succ \hbar_{1} \succ \hbar_{8} .
$$

Then, an optimum set of $U$ is found as follows

$$
O p t_{\kappa}(U)=\left\{\hbar_{3}\right\}
$$

Consequently, $\hbar_{3}$ is an optimal house to buy in this city.

Comparison: Algorithm 1 is compared with the preexisting decision making algorithms based on the soft sets and soft matrices. Thus, it is seen that Algorithm 1 gives more convincing results. The results of these comparisons are in Table 2.

\section{[Insert Table 2]}

In Definition 5.2, we can write $\alpha$-intersection soft matrices and $\alpha$-union soft matrices instead of the classical soft matrices. Then, we consider the following algorithm instead of Algorithm 1.

Algorithm 2. (Set-Restricted Soft Decision Making Algorithm)

Step 1. Decision makers (DMs) choose feasible subsets of the parameter set and then create soft sets.

Step 2. Determine $\alpha_{t}$-sets $(t=1,2, \ldots, r)$. 
Step 3. Construct the soft matrices $\left[a_{i j}^{1}\right],\left[a_{i j}^{2}\right], \ldots,\left[a_{i j}^{r}\right]$.

Step 4. According to the $\alpha_{t}$-sets, create the $\alpha_{t}$-intersection soft matrices $\left[a_{i j}^{1}\right]^{\cap \alpha_{1}}\left[a_{i j}^{2}\right]^{\cap \alpha_{2}}, \ldots,\left[a_{i j}^{r}\right]^{\cap \alpha_{r}}$.

Step 5. Obtain the soft matrices $\left[c_{i p}\right]=\widetilde{\wedge}_{t=1}^{r}\left[a_{i j}^{t}\right]^{\cap \alpha_{t}}$ and $\left[d_{i j}\right]=\widetilde{\cap}_{t=1}^{r}\left[a_{i j}^{t}\right]^{\cap \alpha_{t}}$.

Step 6. Find the aggregate decision triple $\kappa_{i}=\left(\kappa_{i}^{1}, \kappa_{i}^{2}, \kappa_{i}^{3}\right)$ for $i=1,2, \ldots, m$.

Step 7. Obtain the ranking order of objects $\hbar_{i} \in U(i=1,2, \ldots, m)$ and find the optimum set of $U$.

Note: In Step 4 of this algorithm, it can be taken $\alpha_{t}$-union soft matrices instead of $\alpha_{t}$-intersection soft matrices according to the real scenario of the problem.

The step by step procedure of Algorithm 2 (Set-Restricted Soft Decision Making Algorithm) is illustrated in Figure 3.

\section{[Insert Figure 3]}

Example 5.6. Let us consider the decision making problem in Example 5.5.

Step 1. We consider the soft sets $F_{A_{1}}, F_{A_{2}}$ and $F_{A_{3}}$ in Step 1 of Example 5.5.

Step 2. Due to the transportation problems of the big city, Mr. X specifies $\alpha_{1}$ as "close to his workplace", Mrs. $\mathrm{X}$ specifies $\alpha_{2}$ as "close to her workplace" and daughter X specifies $\alpha_{3}$ as "close to her school". Then, the real estate agent offers $\alpha_{1}=\left\{\hbar_{1}, \hbar_{2}, \hbar_{9}\right\}, \alpha_{2}=\left\{\hbar_{6}, \hbar_{8}\right\}$ and $\alpha_{3}=\left\{\hbar_{2}, \hbar_{4}, \hbar_{7}, \hbar_{8}\right\}$, respectively.

Step 3. We consider the soft matrices $\left[a_{i j}^{1}\right],\left[a_{i j}^{2}\right]$ and $\left[a_{i j}^{3}\right]$ in Step 2 of Example 5.5.

Step 4. Then, they create the $\alpha_{t}$-intersection soft matrices for $(t=1,2,3)$ as follows:

$$
\left[a_{i j}^{1}\right]^{\cap \alpha_{1}}=\left[\begin{array}{ccc}
0 & 1 & 1 \\
0 & 1 & 0 \\
0 & 0 & 1 \\
0 & 1 & 1 \\
0 & 1 & 0 \\
0 & 0 & 1 \\
0 & 1 & 1 \\
0 & 0 & 1 \\
0 & 0 & 0
\end{array}\right],\left[a_{i j}^{2}\right]^{\cap \alpha_{2}}=\left[\begin{array}{ccc}
0 & 0 & 0 \\
0 & 1 & 0 \\
0 & 0 & 1 \\
0 & 1 & 1 \\
0 & 1 & 0 \\
0 & 0 & 1 \\
0 & 1 & 0 \\
0 & 1 & 0 \\
0 & 1 & 1
\end{array}\right] \text { and }\left[a_{i j}^{3}\right]^{\cap \alpha_{3}}=\left[\begin{array}{ccc}
0 & 0 & 0 \\
0 & 1 & 0 \\
0 & 1 & 0 \\
0 & 1 & 0 \\
0 & 1 & 0 \\
0 & 1 & 0 \\
0 & 1 & 0 \\
0 & 0 & 0 \\
0 & 1 & 0
\end{array}\right] .
$$

Step 5. They obtain the soft matrices

$$
\begin{aligned}
& {\left[c_{i p}\right]=\widetilde{\wedge}_{t=1}^{3}\left[a_{i j}^{t}\right]^{\cap \alpha_{t}}=} \\
& {\left[\begin{array}{lllllllllllllllllllllllllll}
0 & 0 & 0 & 0 & 0 & 0 & 0 & 0 & 0 & 0 & 0 & 0 & 0 & 0 & 0 & 0 & 0 & 0 & 0 & 0 & 0 & 0 & 0 & 0 & 0 & 0 & 0 \\
0 & 0 & 0 & 0 & 0 & 0 & 0 & 0 & 0 & 0 & 0 & 0 & 0 & 1 & 0 & 0 & 0 & 0 & 0 & 0 & 0 & 0 & 0 & 0 & 0 & 0 & 0 \\
0 & 0 & 0 & 0 & 0 & 0 & 0 & 0 & 0 & 0 & 0 & 0 & 0 & 0 & 0 & 0 & 0 & 0 & 0 & 0 & 0 & 0 & 0 & 0 & 0 & 1 & 0 \\
0 & 0 & 0 & 0 & 0 & 0 & 0 & 0 & 0 & 0 & 0 & 0 & 0 & 1 & 0 & 0 & 1 & 0 & 0 & 0 & 0 & 0 & 1 & 0 & 0 & 1 & 0 \\
0 & 0 & 0 & 0 & 0 & 0 & 0 & 0 & 0 & 0 & 0 & 0 & 0 & 1 & 0 & 0 & 0 & 0 & 0 & 0 & 0 & 0 & 0 & 0 & 0 & 0 & 0 \\
0 & 0 & 0 & 0 & 0 & 0 & 0 & 0 & 0 & 0 & 0 & 0 & 0 & 0 & 0 & 0 & 0 & 0 & 0 & 0 & 0 & 0 & 0 & 0 & 0 & 1 & 0 \\
0 & 0 & 0 & 0 & 0 & 0 & 0 & 0 & 0 & 0 & 0 & 0 & 0 & 1 & 0 & 0 & 0 & 0 & 0 & 0 & 0 & 0 & 1 & 0 & 0 & 0 & 0 \\
0 & 0 & 0 & 0 & 0 & 0 & 0 & 0 & 0 & 0 & 0 & 0 & 0 & 0 & 0 & 0 & 0 & 0 & 0 & 0 & 0 & 0 & 0 & 0 & 0 & 0 & 0 \\
0 & 0 & 0 & 0 & 0 & 0 & 0 & 0 & 0 & 0 & 0 & 0 & 0 & 0 & 0 & 0 & 0 & 0 & 0 & 0 & 0 & 0 & 0 & 0 & 0 & 0 & 0
\end{array}\right]} \\
& \text { and }
\end{aligned}
$$




$$
\left[d_{i j}\right]=\widetilde{\cap}_{t=1}^{3}\left[a_{i j}^{t}\right]^{\cap \alpha_{t}}=\left[\begin{array}{ccc}
0 & 0 & 0 \\
0 & 1 & 0 \\
0 & 0 & 0 \\
0 & 1 & 0 \\
0 & 1 & 0 \\
0 & 0 & 0 \\
0 & 1 & 0 \\
0 & 0 & 0 \\
0 & 0 & 0
\end{array}\right] .
$$

Step 6. The aggregate decision triple for each $i=1,2, \ldots, 9$ is found as in Table 3 .

\section{[Insert Table 3]}

Figure 4 presents a graphical representation of aggregate decision triples in Table 3.

\section{[Insert Figure 4]}

Step 7. Then, the ranking order of houses is obtained as

$$
\hbar_{4} \succ \hbar_{7} \succ \hbar_{2}=\hbar_{5} \succ \hbar_{3}=\hbar_{6} \succ \hbar_{9} \succ \hbar_{1}=h_{8} .
$$

Then, an optimum set of $U$ is found as follows

$$
O p t_{\kappa}(U)=\left\{\hbar_{4}\right\} .
$$

Consequently, $\hbar_{4}$ is an optimal house to buy in this city under the $\alpha_{t}$-sets.

\section{Advantages and limitations of proposed approaches}

First, let us talk about the advantages of the proposed decision making models. The proposed soft decision making model (Algorithm 1) presents more convincing outputs than some existing soft decision making models for multi-criteria decision making problems under the soft set environment (see comparison results in Table 2). The set-restricted soft decision making model (Algorithm 2) can deal with soft set-based multi-criteria decision making involving primary assessments. In conclusion, the advantages of the proposed decision making approaches is that both produce more satisfactory results than existing soft decision making approaches and present solutions for multi-criteria decision making problems involving primary considerations that existing approaches cannot cope with.

To present the limitations of the proposed approaches, we critically analyze Algorithm 1 and Algorithm 2 and thus give following drawbacks: In Examples 5.5 and 5.6, possible dependencies between parameters are neglected. It is not always possible in practice to suppose in the multi-criteria decision making that each parameter is independent of other parameters. Any parameter in the multi-criteria decision making could be related to, or dependent on other parameters. In the proposed approaches, evaluating the dependencies among parameters should contribute to the objectivity of decisions. By considering dependencies between parameters in the soft set-based multi-criteria decision making, the quality of decision making process may be improved.

\section{Conclusion}

In this study, we introduced many new and useful concepts such as, the $\alpha$-intersection set and $\alpha$-union set of soft sets, and the types of $\alpha$-upper, $\alpha$-lower, $\alpha$-intersection and $\alpha$-union of soft matrices. Also, we gave some decomposition theorems for both soft sets and soft matrices. It was proved that the relationships between soft sets and soft matrices are also valid for their decompositions. To show that these emerged decompositions will be very useful in solving decision making problems involving constraint conditions, new soft decision making 
models were proposed.

In the future, these decompositions are expect to lead to new studies in soft sets and soft matrices. Furthermore, the proposed decision making approaches would be beneficial for applications in new research areas. In addition to these, the $\alpha$-oriented concepts proposed in this paper can be adapted for the fuzzy soft sets, intuitionistic fuzzy soft sets, Pythagorean fuzzy soft sets, q-rung orthopair fuzzy soft sets, picture fuzzy soft sets, spherical fuzzy soft sets, T-spherical fuzzy soft sets, linear Diophantine fuzzy soft sets, neutrosophic soft sets and their extensions. Our future research topic will also serve these purposes.

\section{Appendix}

\section{Scilab Codes:}

We give the following Scilab codes for convenience of the steps in the above soft decision making algorithms. Through these codes, it is possible to solve the group decision making problems involving a large number of decision makers.

\begin{tabular}{|c|c|c|c|}
\hline \multicolumn{2}{|c|}{ for $A n d$-product and Multi- $A n d$-product $(\widetilde{\wedge})$} & \multicolumn{2}{|c|}{ for intersection and Multi-intersection $(\widetilde{\cap})$} \\
\hline \multicolumn{2}{|c|}{ 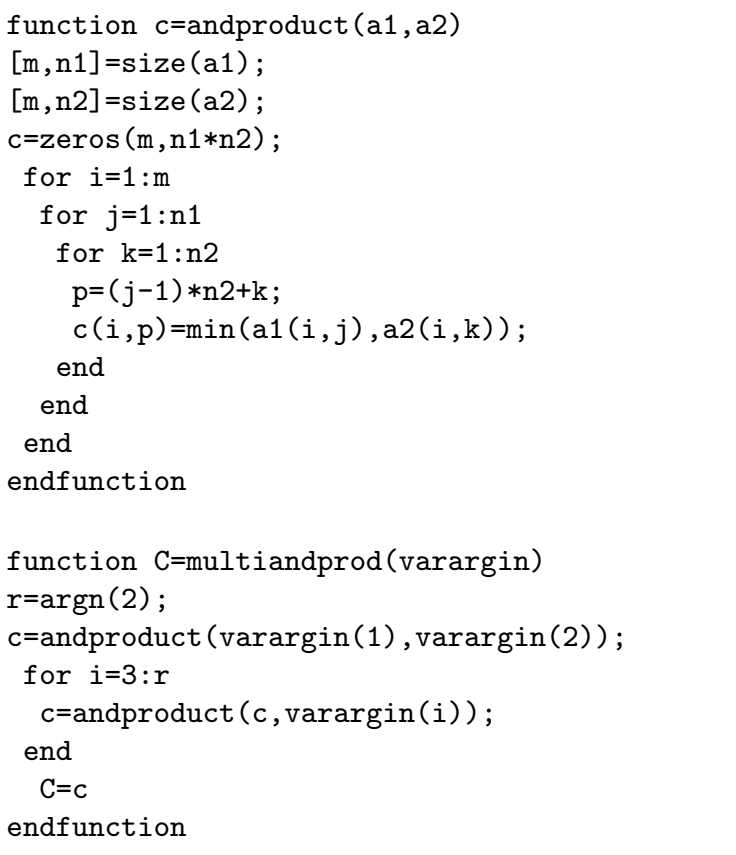 } & \multicolumn{2}{|c|}{ 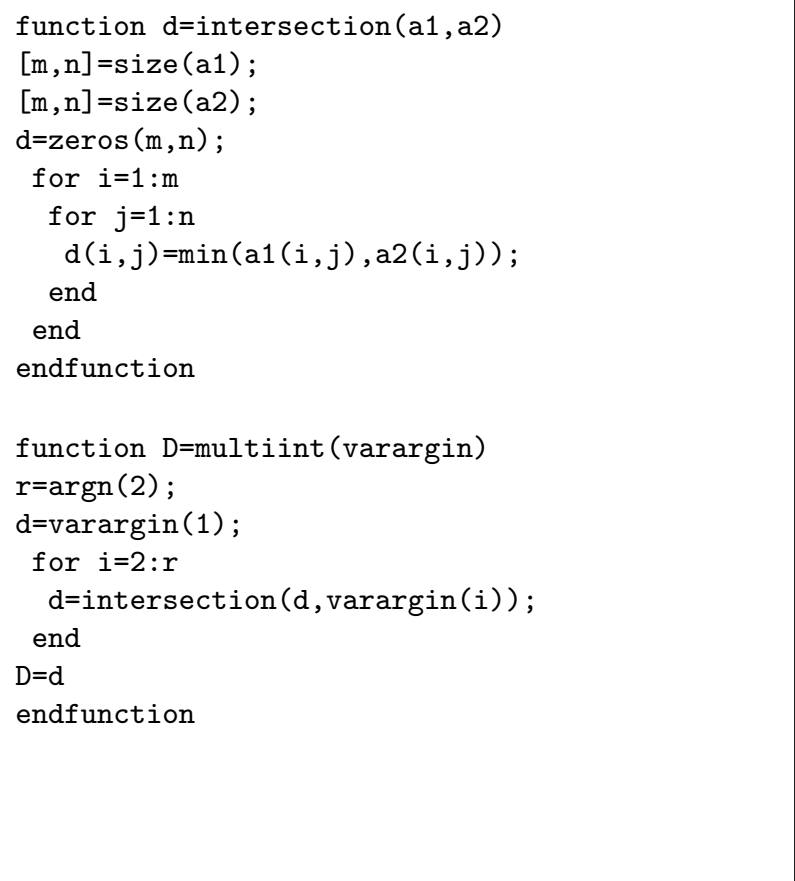 } \\
\hline for $\kappa^{1}$ & \multicolumn{2}{|l|}{ for $\kappa^{2}$} & for $\kappa^{3}$ \\
\hline $\begin{array}{l}\text { function } K 1=\text { aggregate } 1(C) \\
K 1=\operatorname{sum}\left(C, C^{\prime}\right) \text {; } \\
\text { endfunction }\end{array}$ & \multicolumn{2}{|c|}{$\begin{array}{l}\text { function } \mathrm{K} 2=\operatorname{aggregate} 2 \text { (varargin) } \\
\mathrm{r}=\operatorname{argn}(2) ; \\
\mathrm{s}=\operatorname{varargin}(1) ; \\
\text { for } i=2: \mathrm{r} \\
\quad \mathrm{s}=\mathrm{s}+\operatorname{varargin}(i) ; \\
\text { end } \\
\mathrm{k} 2=\operatorname{sum}(\mathrm{s}, 2) ; \\
\mathrm{K} 2=\mathrm{k} 2 \\
\text { endfunction }\end{array}$} & $\begin{array}{l}\text { function } K 3=\text { aggregate3 (varargin) } \\
\text { r=length (varargin); } \\
\text { K3=r*sum }(D, \text { ' } C \text { '); } \\
\text { endfunction }\end{array}$ \\
\hline
\end{tabular}




\section{References}

[1] Zadeh L. A. "Fuzzy sets", Information Control 8(3), pp. 338-353 (1965).

[2] Guleria, A. and Bajaj, R. K. "Eigen spherical fuzzy set and its application to decision-making problem", Scientia Iranica E, 28(1), pp. 516531 (2021).

[3] Jana, C., Pal, M., Karaaslan, F. and Wang, J.-q. "Trapezoidal neutrosophic aggregation operators and their application to the multi-attribute decision-making process", Scientia Iranica E, 27(3), pp. 16551673 (2020).

[4] Kumar, T., Bajaj, R. and Ansari, M.D. "On accuracy function and distance measures of interval-valued Pythagorean fuzzy sets with application to decision making", Scientia Iranica E, 27(4), pp. 2127-2139 (2020).

[5] Peng, X. "New operations for interval-valued Pythagorean fuzzy set", Scientia Iranica E, 26(2), pp. 10491076 (2019).

[6] Tang, J. and Meng, F. "An approach to interval-valued intuitionistic fuzzy decision making based on induced generalized symmetrical Choquet-Shapley operator", Scientia Iranica D, 25(3), pp. 1456-1470 (2018).

[7] Molodtsov, D. "Soft set theory-first results", Computers and Mathematics with Applications, 37, pp. 19-31 (1999).

[8] Maji, P.K., Biswas, R. and Roy, A.R. "Soft set theory", Computers and Mathematics with Applications, 45, pp. 555-562 (2003).

[9] Ali, M.I., Feng, F., Liu, X., Min, W.K. and Shabir, M. "On some new operations in soft set theory" Computers and Mathematics with Applications, 57, pp. 1547-1553 (2009).

[10] Pei, D. and Miao, D. "From sets to information systems", in: Hu, X., Liu, Q., Skowron, A., Lin, T.Y., Yager, R.R. and Zhang B. (Eds.). Proceedings of Granular Computing IEEE, 2, pp. 617-621 (2005).

[11] Kamac1, H. "Similarity measure for soft matrices and its applications", Journal of Intelligent and Fuzzy Systems, 36, pp. 3061-3072 (2019).

[12] Kamacı, H., Atagün, A.O. and Aygün, E. "Difference operations of soft matrices with applications in decision making", Punjab University Journal of Mathematics, 51, pp. 1-21 (2019).

[13] Sezgin, A. and Atagün, A.O. "On operations of soft sets", Computers and Mathematics with Applications, 61, pp. 1457-1467 (2011).

[14] Aygün, E. and Kamac1, H. "Some generalized operations in soft set theory and their role in similarity and decision making", Journal of Intelligent and Fuzzy Systems, 36, pp. 6537-6547 (2019).

[15] Çag̃man, N. and Enginog̃lu, S. "Soft set theory and uni-int decision making", European Journal of Operational Research 207, pp. 848-855 (2010).

[16] Feng, F., Akram, M., Davvaz, B. and Leoreanu-Fotea, V. "Attribute analysis of information systems based on elementary soft implications", Knowledge-Based Systems, 70, pp. 281-292 (2014).

[17] Aktaş, H. and Çağman, N. "Soft sets and soft groups", Information Sciences, 177, pp. 2726-2735 (2007).

[18] Atagün, A.O. and Aygün, E. "Groups of soft sets", Journal of Intelligent and Fuzzy Systems, 30, pp. 729-733 (2016). 
[19] Ayup, S., Shabir, M. and Mahmood, W. "New types of soft rough sets in groups based on normal soft groups", Computational and Applied Mathematics, 39, pp. 67 (2020).

[20] Sezer, A.S., Çag̃man, N., Atagün, A.O., Ali, M.I. and Türkmen, E. "Soft intersection semigroups, ideals and bi-ideals; a new application on semigroup theory I", Filomat, 29, pp. 917-946 (2015).

[21] Feng, F., Jun, Y.B. and Zhao, X. "Soft semirings", Computers and Mathematics with Applications, 56, pp. 2621-2628 (2008).

[22] Acar, U., Koyuncu, F. and Tanay. B. "Soft sets and soft rings", Computers and Mathematics with Applications, 59(11), pp. 3458-3463 (2010).

[23] Liu, X., Xiang, D., Zhan, J. and Shum, K.P. "Isomorphism theorems for soft rings", Algebra Colloquium, 19, pp. 649-656 (2012).

[24] Sezgin, A., Atagün, A.O. and Aygün, E. "A note on soft near-rings and idealistic soft near-rings", Filomat, 25, pp. 53-68 (2011).

[25] Akram, M. and Feng, F. "Soft intersection Lie algebras", Quasigroups and Related Systems, 21, pp. 11-18 (2013).

[26] Karaaslan, F., Çag̃man, N. and Engiog̃lu, S. "Soft lattices", Journal of New Results in Science, 1, pp. 5-17 (2012).

[27] Shabir, M., Kanwal, S., Bashir, S. and Mazhar, R. "An isomorphic approach of fuzzy soft lattices to fuzzy soft Priestley spaces", Computers and Mathematics with Applications, 39, pp. 312 (2020).

[28] Susanta, B., Roy, S.K., Karaaslan, F. and Çag̃man, N. "Soft congruence relation over lattice", Hacettepe Journal of Mathematics and Statistics, 46, pp. 1035-1042 (2017).

[29] Ullah, A., Karaaslan, F. and Ahmad, I. "Soft uni-Abel-Grassmann's groups", European Journal of Pure and Applied Mathematics, 11, pp. 517-536 (2018).

[30] Akram, M. and Nawaz, S. "Operations on soft graphs", Fuzzy Information and Engineering, 7, pp. 423-449 (2015).

[31] Akram, M. and Nawaz, S. "Fuzzy soft graphs with applications", Journal of Intelligent and Fuzzy Systems, 30, pp. 3619-3631 (2016).

[32] Jun, Y.B. "Soft BCK/BCI-algebras", Computers and Mathematics with Applications, 56, pp. 1408-1413 (2008).

[33] Jun, Y.B. and Park, C.H. "Applications of soft sets in ideal theory of BCK/BCI-algebras", Information Sciences, 178, pp. 2466-2475 (2008).

[34] Jun, Y.B., Lee, K.J. and Zhan, J. "Soft p-ideals of soft BCI-algebras", Computers and Mathematics with Applications, 58, pp. 2060-2068 (2009).

[35] Zhan, J. and Jun, Y.B. "Soft BL-algebras based on fuzzy sets", Computers and Mathematics with Applications, 59, pp. 2037-2046 (2010).

[36] Çag̃man, N. and Deli, I. "Means of FP-soft sets and their applications", Hacettepe Journal of Mathematics and Statistics, 41, pp. 615-625 (2012).

[37] Deli, I. and Çag̃man, N. "Fuzzy soft games", Filomat 29, pp. 1901-1917 (2015). 
[38] Peng, X. and Garg, H. "Algorithms for interval-valued fuzzy soft sets in emergency decision making based on WDBA and CODAS with new information measure", Computers and Industrial Engineering, 119, pp. 439-452 (2018).

[39] Arora, R. and Garg, H. "Prioritized averaging/geometric aggregation operatorsunder the intuitionistic fuzzy soft set environment", Scientia Iranica E, 25(1), pp. 466-482 (2018).

[40] Arora, R. and Garg, H. "Robust aggregation operators for multi-criteriadecision-making with intuitionistic fuzzy soft setenvironment", Scientia Iranica E, 25(2), pp. 931-942 (2018).

[41] Garg, H. and Arora, R. "Generalized Maclaurin symmetric mean aggregation operators based on Archimedean t-norm of the intuitionistic fuzzy soft set information", Artificial Intelligence Review, 54, pp. 31733213 (2021).

[42] Quek, S.G., Selvachandran, G., Davvaz, B. and Pal, M. "The algebraic structures of complex intuitionistic fuzzy soft sets associated with groups and subgroups", Scientia Iranica E, 26(3), pp.1898-1912 (2019).

[43] Guleria, A. and Bajaj, R. K. "T -spherical fuzzy soft sets and its aggregation operators with application in decision-making", Scientia Iranica E, 28(2), pp. 10141029 (2021).

[44] Riaz, M., Smarandache, F., Karaaslan, F., Hashmi, M.R. and Nawaz, I. "Neutrosophic soft rough topology and its applications to multi-criteria decision-making", Neutrosophic Sets and Systems, 35, pp. 198-219 (2020).

[45] Tehrim, S.T. and Riaz, M. "A novel extension of TOPSIS to MCGDM with bipolar neutrosophic soft topology", Journal of Intelligent and Fuzzy Systems, 37, pp. 5531-5549 (2019).

[46] Akçetin, E. and Kamacı, H. "Three-valued soft set and its multi-criteria group decision making via TOPSIS and ELECTRE", Scientia Iranica, in press (2020). DOI: 10.24200/sci.2020.54715.3881.

[47] Akram, M., Adeel, A. and Alacantud, J.C.R. "Fuzzy N-soft sets: A novel model with applications", Journal of Intelligent and Fuzzy Systems, 35(4), pp. 4757-4771 (2018).

[48] Akram, M., Ali, G. and Alacantud, J.C.R. "New decision-making hybrid model: intuitionistic fuzzy N-soft rough sets", Soft Computing, 23, pp. 4757-4771 (2018).

[49] Kamac1, H. "Introduction to N-soft algebraic structures", Turkish Journal of Mathematics, 44(6), pp. 23562379 (2020).

[50] Kamacı, H. and Petchimuthu S. "Bipolar N-soft set theory with applications", Soft Computing, 24, pp. 16727-16743 (2020).

[51] Çag̃man, N. and Enginog̃lu, S. "Soft matrix theory and its decision making", Computers and Mathematics with Applications, 59(10), pp. 3308-3314 (2010).

[52] Atagün, A.O., Kamacı, H. and Oktay, O. "Reduced soft matrices and generalized products with applications in decision making", Neural Computing and Applications 29, pp. 445-456 (2018).

[53] Kamacı, H., Atagün, A.O. and Sönmezog̃lu, A. "Row-products of soft matrices with applications in multipledisjoint decision making", Applied Soft Computing, 62, pp. 892-914 (2018).

[54] Petchimuthu, S. and Kamac1, H. "The row-products of inverse soft matrices in multicriteria decision making", Journal of Intelligent and Fuzzy Systems, 36(6), pp. 6425-6441 (2019). 
[55] Petchimuthu, S. and Kamacı, H. "The adjustable approaches to multi-criteria group decision making based on inverse fuzzy soft matrices", Scientia Iranica, in press (2020). DOI: 10.24200/sci.2020.54294.3686.

[56] Basu, T.M., Mahapatra, N.M. and Mondal, S.K. "Matrices in soft set theory and their applications in decision making problems", South Asian Journal of Mathematics, 2, pp. 126-143 (2012).

[57] Kamacı, H., Atagün, A.O. and Toktas,, E. "Bijective soft matrix theory and multi-bijective linguistic soft decision system", Filomat, 32(11), pp. 3799-3814 (2018).

[58] Kamacı, H., Saltık, K., Akız, H.F. and Atagün, A.O. "Cardinality inverse soft matrix theory and its applications in multicriteria group decision making", Journal of Intelligent and Fuzzy Systems, 34, pp. 2031-2049 (2018).

[59] Vijayabalaji, S. and Ramesh, A. "A new decision making theory in soft matrices", International Journal of Pure and Applied Mathematics, 86, pp. 927-939 (2013).

[60] Eraslan, S. "A decision making method via TOPSIS on soft sets", Journal of New Results in Science, 8, pp. $57-71(2015)$.

[61] Feng, F., Li, Y. and Çag̃man, N. "Generalized uni-int decision making schemes based on choice value soft sets", European Journal of Operational Research, 220, pp. 162-170 (2012).

[62] Han, B.H. and Geng, S.L. "Pruning method for optimal solutions of $i n t^{m}-i n t^{n}$ decision making scheme". European Journal of Operational Research, 231, pp. 779-783 (2013).

[63] Kharal, A. "Soft approximations and uni-int decision making", The Scientific World Journal, 2014, 7 pages (2014).

\section{Biographies}

Akın Osman Atagün is a Professor at the Department of Mathematics, Faculty of Science and Arts, Kırşehir Ahi Evran University in Turkey. He received his MSc degree in Mathematics from Kirıkkale University, Turkey in 2001 and $\mathrm{PhD}$ degree in Mathematics from Erciyes University, Turkey in 2006. His research interests are in the areas of soft set theory, soft matrix theory, rough set theory, algebraic structures, operational research, soft computing and decision making. He has published many valuable articles on these scientific topics in international academic journals including Computers \& Mathematics with Applications, Neural Computing and Applications, Applied Soft Computing, Computational and Applied Mathematics, Hacettepe Journal of Mathematics and Statistics, Scientia Iranica, Journal of Intelligent \& Fuzzy Systems, Indian Journal of Pure and Applied Mathematics, Information Sciences Letters, Journal of Algebra, Number Theory and Applications, Southeast Asian Bulletin of Mathematics, Filomat, Punjab University Journal of Mathematics, etc.

Hüseyin Kamacı is a Research Assistant at the Mathematics Department in the Science and Arts Faculty of Yozgat Bozok University, Turkey. He received his MSc and PhD degrees in Mathematics from Bozok University, Yozgat, Turkey in 2014 and 2018, respectively. His research interests include mathematical logic, fuzzy set, rough set, soft set, soft matrix, operational research, computational intelligence, decision making and game theory. He has many valuable publications on these issues in different scientific journals. 


\section{Figures and Tables}

\section{Figure Captions:}

Figure 1: The framework of Algorithm 1

Figure 2: Graphical representation of aggregate decision triples

Figure 3: The framework of Algorithm 2

Figure 4: Graphical representation of aggregate decision triples

\section{Table Captions:}

Table 1: Tabular form of the aggregate decision triples.

Table 2: Comparison result of Algorithm 1 with some existing soft decision making algorithms in the literature.

Table 3: Tabular form of the aggregate decision triples.

\section{List of Figures:}

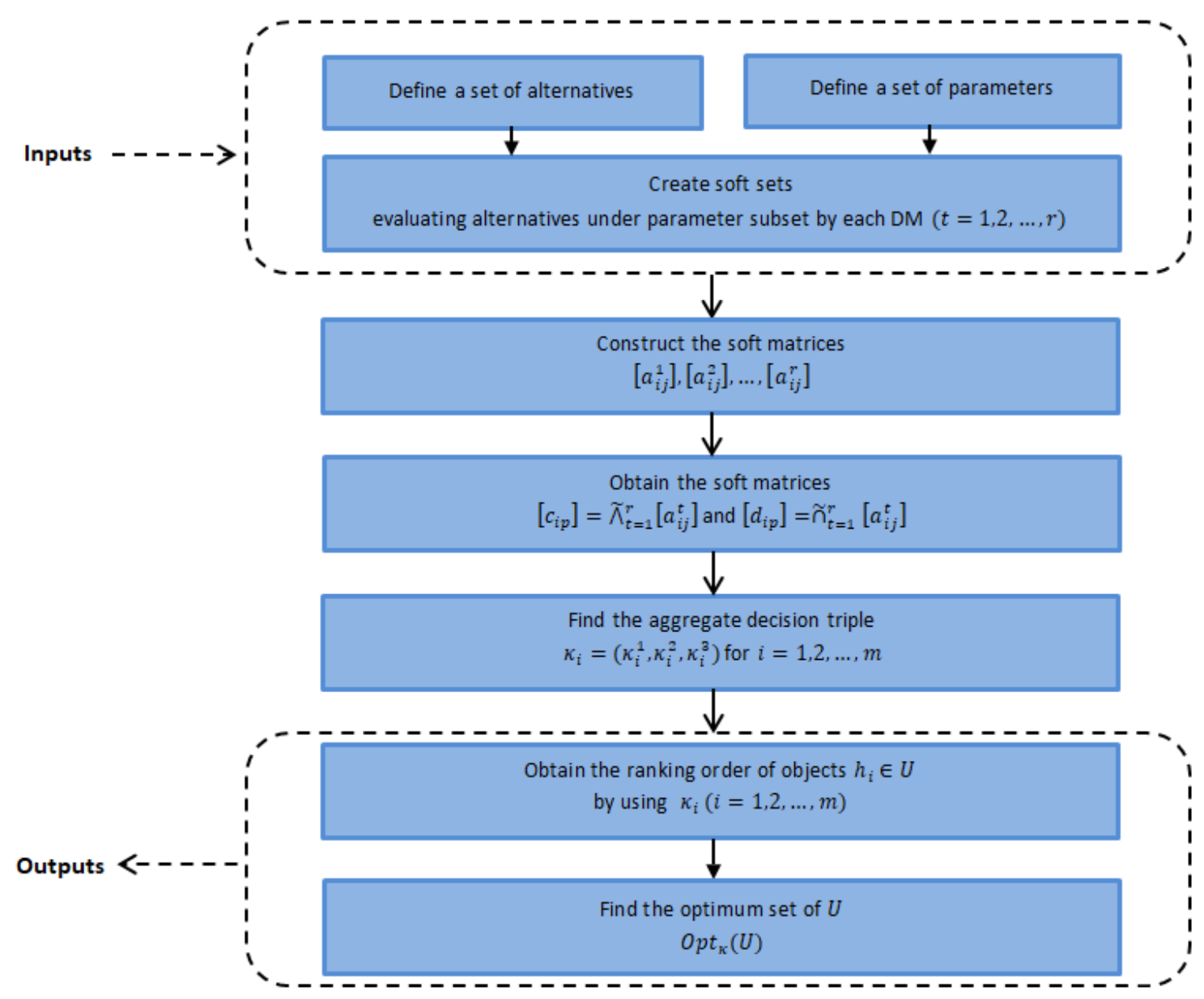

Figure 1: The framework of Algorithm 1 


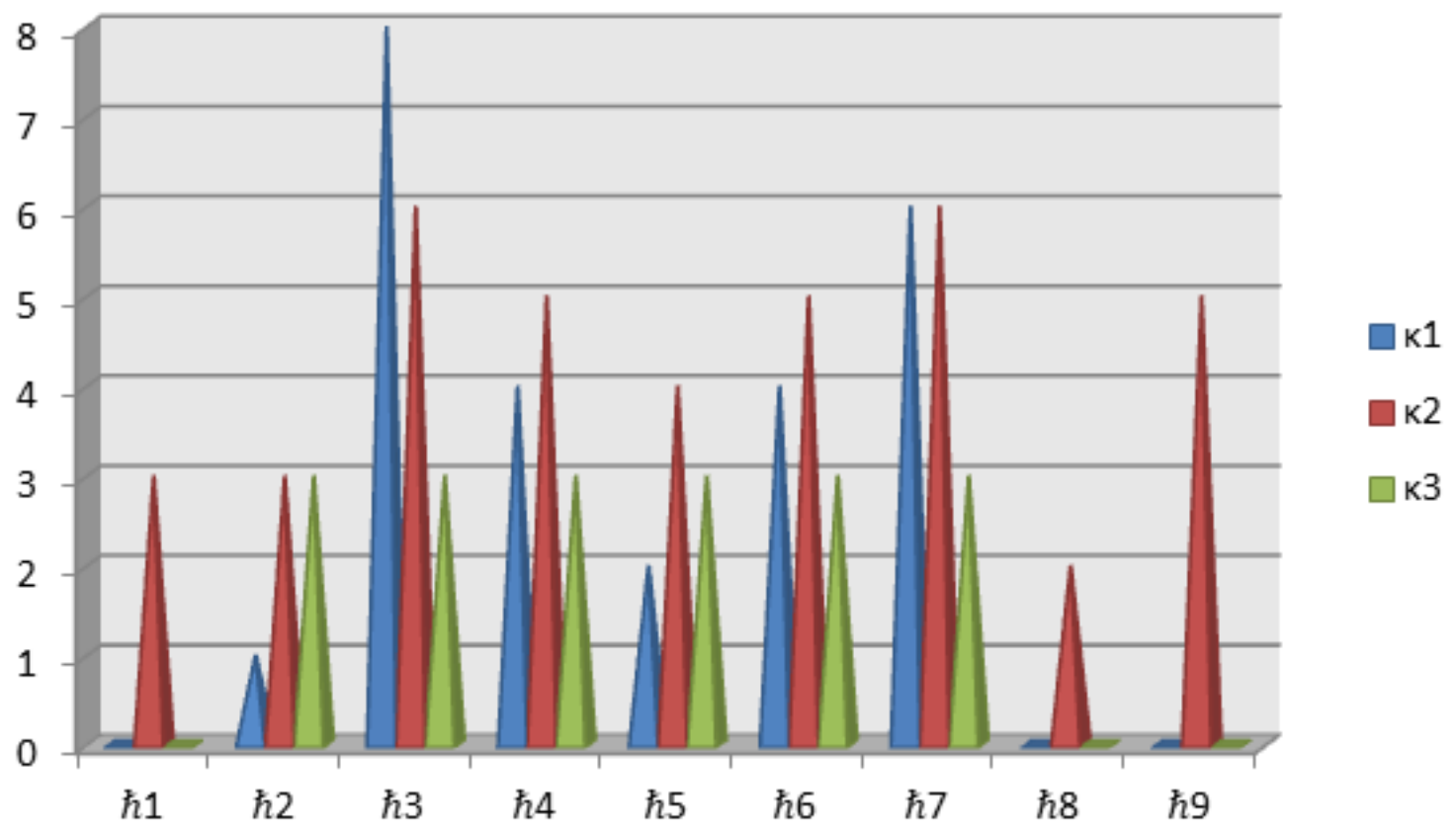

Figure 2: Graphical representation of aggregate decision triples 


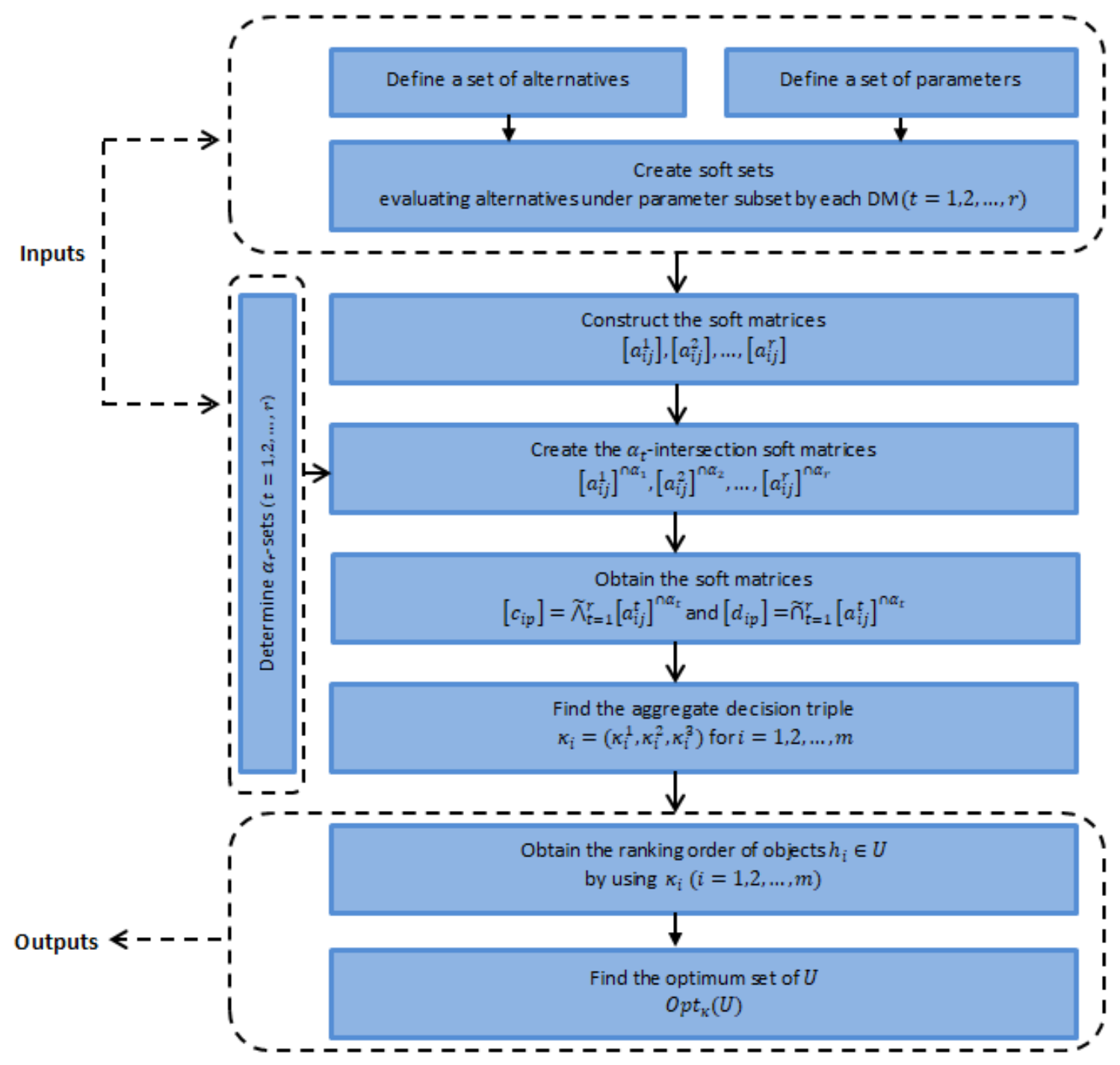

Figure 3: The framework of Algorithm 2 


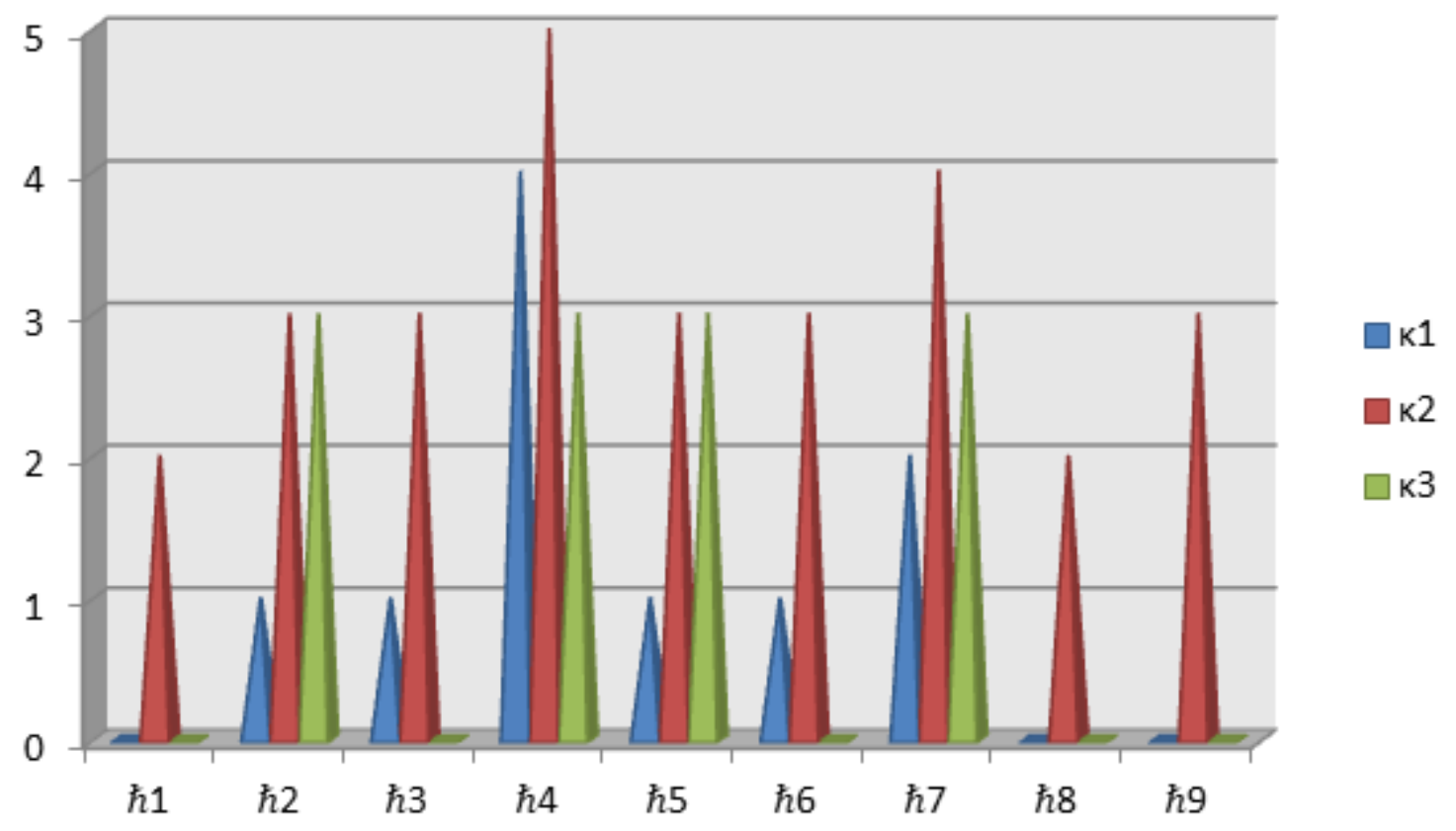

Figure 4: Graphical representation of aggregate decision triples 


\section{List of Tables:}

Table 1: Tabular form of the aggregate decision triples

\begin{tabular}{cccccccccc}
\hline$\kappa_{i} / i$ & 1 & 2 & 3 & 4 & 5 & 6 & 7 & 8 & 9 \\
\hline$\kappa_{i}=\left(\kappa_{i}^{1}, \kappa_{i}^{2}, \kappa_{i}^{3}\right)$ & $(0,3,0)$ & $(1,3,3)$ & $(8,6,3)$ & $(4,5,3)$ & $(2,4,3)$ & $(4,5,3)$ & $(6,6,3)$ & $(0,2,0)$ & $(0,5,0)$ \\
\hline
\end{tabular}

Table 2: Comparison result of Algorithm 1 with some existing soft decision making algorithms in the literature

\begin{tabular}{llll}
\hline Paper & Problem in the paper & Result of their algorithm & Result of Algorithm 1 for same problem \\
\hline$[52]$ & Example 5.1 in [52] & $\left\{u_{1}, u_{3}\right\}$ & $u_{3} \succ u_{1} \succ u_{4} \succ u_{5} \succ u_{2}$ \\
{$[56]$} & Example 5.1 in [56] & $\left\{d_{2}, d_{3}\right\}$ & $d_{3} \succ d_{2} \succ d_{1} \succ d_{4}$ \\
{$[56]$} & Example 5.2 in [56] & $\left\{f_{1}\right\}$ & $f_{1} \succ f_{4} \succ f_{2} \succ f_{3}$ \\
{$[51]$} & Example 6 in [51] & $\left\{u_{1}\right\}$ & $u_{1} \succ u_{2} \succ u_{3} \succ u_{5} \succ u_{4}$ \\
{$[15]$} & Example in [15] & $\left\{u_{4}, u_{13}, u_{21}, u_{36}, u_{42}\right\}$ & $u_{13}=u_{36} \succ u_{21} \succ u_{42} \succ u_{28} \succ u_{4}$ \\
{$[60]$} & Application in [60] & $u_{1}>u_{3}>u_{2}$ & $u_{1} \succ u_{3} \succ u_{2}$ \\
{$[61]$} & Example 5.17 in [61] & $\left\{h_{1}, h_{2}, h_{3}\right\}$ & $h_{1}=h_{3} \succ h_{2} \succ h_{4}=h_{5}$ \\
{$[61]$} & Example 5.19 in [61] & $\left\{u_{13}, u_{36}\right\}$ & $u_{13}=u_{36} \succ u_{21} \succ u_{42} \succ u_{28} \succ u_{4}$ \\
{$[62]$} & Example 3.3 in [62] $\left\{h_{1}, h_{2}, h_{3}\right\}$ & $h_{1}=h_{3} \succ h_{2} \succ h_{4}=h_{5}$ \\
{$[63]$} & Example 31 in [63] & $\left\{u_{3}\right\}$ & $u_{3} \succ u_{2} \succ u_{4} \succ u_{5} \succ u_{1}$ \\
{$[59]$} & Example 3.10 in [59] $\left\{m_{3}\right\}$ & $m_{3} \succ m_{5} \succ m_{2} \succ m_{1} \succ m_{4}$ \\
{$[59]$} & Example 3.12 in [59] & $\left\{m_{3}\right\}$ & $m_{3} \succ m_{1} \succ m_{2}=m_{5} \succ m_{4}$ \\
\hline
\end{tabular}

Table 3: Tabular form of the aggregate decision triples

\begin{tabular}{cccccccccc}
\hline$\kappa_{i} / i$ & 1 & 2 & 3 & 4 & 5 & 6 & 7 & 8 & 9 \\
\hline$\kappa_{i}=\left(\kappa_{i}^{1}, \kappa_{i}^{2}, \kappa_{i}^{3}\right)$ & $(0,2,0)$ & $(1,3,3)$ & $(1,3,0)$ & $(4,5,3)$ & $(1,3,3)$ & $(1,3,0)$ & $(2,4,3)$ & $(0,2,0)$ & $(0,3,0)$ \\
\hline
\end{tabular}

